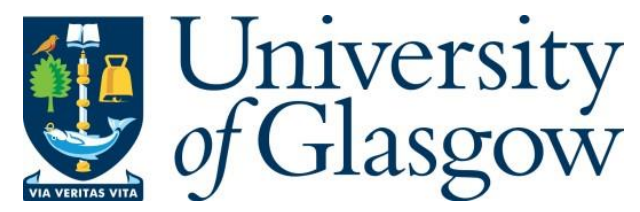

Cao, D., Chen, H. and Yuan, J. (2021) Inline force on human body due to non-impulsive wave overtopping at a vertical seawall. Ocean Engineering, 219, 108300.

There may be differences between this version and the published version. You are advised to consult the publisher's version if you wish to cite from it.

$\underline{\text { http://eprints.gla.ac.uk/249163/ }}$

Deposited on: 10 August 2021

Enlighten - Research publications by members of the University of Glasgow http://eprints.gla.ac.uk 


\title{
Inline force on human body due to non-impulsive wave overtopping at a vertical seawall
}

\author{
Deping Cao ${ }^{\mathrm{a},}$, Hao Chen ${ }^{\mathrm{a}, *}$, Jing Yuan ${ }^{\mathrm{a}}$ \\ ${ }^{a}$ Department of Civil and Environmental Engineering, National University of Singapore, Singapore.
}

\begin{abstract}
Wave overtopping endangers pedestrians on a seawall's crest area, but quantitative assessment of the risk is still a challenge. In this study, a circular cylinder is taken as a schematisation of human body. Physical model tests and numerical simulations were conducted to investigate the inline force on the cylinder due to overtopping flow at a vertical seawall. It is found that the overtopping flow is well reproduced by the numerical model. When the overtopping flow encounters the cylinder, a high pressure zone is developed on the front surface of the cylinder due to the local flow stagnation, while a shallow wake flow occurs behind the cylinder due to the blockage effect. The asymmetric pressure distribution produces the inline force on the cylinder. When the cylinder is further moved inland, the depth of the local overtopping flow it faces is smaller. However, the inline force does not decay accordingly, which is due to the variation of the flow velocity along the seawall's crest. Finally, a predictor is developed for desktop computation of the maximum inline force. A prototype-scale numerical case study is carried out to demonstrate the capability of this predictor.
\end{abstract}

Keywords: Vertical seawall; Wave overtopping; Inline force; Flow-cylinder interaction.

\section{Introduction}

Seawalls are key elements for coastal protection, especially for highly urbanized coastal area (e.g., the island state of Singapore). The seawalls' crest areas often attract many pedestrians. Their safety may be threatened by wave overtopping, which occurs when the crest level of the seawall is lower than the possible wave runup. A strong overtopping flow can knock down the pedestrians standing on the seawall. It was reported by Allsop et al. (2003) that at least 12 people died due to wave overtopping in UK between 1999 and 2002. EurOtop (2018) also reported that 11 people were killed in UK in 2005 through wave action, mainly on seawalls and other similar coastal structures. Hereby it is of vital importance to ensure that the seawalls are well designed to protect pedestrians from being threatened by the overtopping flow. The

\footnotetext{
${ }^{*}$ Corresponding author. Present address: School of Engineering, University of Glasgow, Glasgow, UK. Email address:
} Hao.Chen@glasgow.ac.uk 
existing guidelines such as EurOtop (2018) have introduced indicative tolerable overtopping conditions for people on seawalls' crest, but these conditions are empirically determined and therefore relatively crude. A thorough study is needed for enhancing our knowledge on the hydrodynamic process and refining the guideline in the future.

A substantial amount of research works have been carried out towards understanding the hydrodynamics of wave overtopping process, of which a majority are targeted at sloped structures such as revetments and rubble-mound breakwaters (Romano et al., 2015, Jensen et al. 2014, Schüttrumpf and Oumeraci, 2005, Van der Meer et al., 2011; Mares-Nasarre et al., 2019, Van Bergeijk et al., 2019; Guo et al., 2013). Vertical seawalls are also common coastal protection structures, but there are fewer studies on this type of structures. For the assessment of overtopping at vertical structures, it is generally required to identify the regime of the waves arriving at the seawall. When wave height is large in relation to the local water depth, e.g., when the seawall sits on a shallow foreshore, they may break in front of the seawall, and the breaking waves strike violently onto the wall, producing a short-duration impulsive load (Cuomo et al., 2010, Cooker and Peregrine, 1992, Bullock et al., 2007, Bredmose et al., 2009, 2015). Alternatively, lying in a narrow band between non-impulsive and impulsive conditions are near-breaking conditions, also known as the flipthrough conditions (Bredmose et al. 2010, Lugni et al., 2006). The overtopping flow under these conditions is characterised by a violent up-rushing jet of probably highly aerated water, and the overtopping discharge rate can be described by a power law formulation (EurOtop, 2018).

Some of the vertical seawalls or breakwaters are concrete caissons, which are placed in deep water. In the present paper, we shall focus on the overtopping forces on human body under such condition. Fig. 1 shows an example of the vertical seawall at a marina in Singapore, which is open to public. In this case, the foreshore has little effects on wave propagation and waves simply arrive at the vertical seawall without breaking. The incident waves are largely reflected back by the seawall, and a green water overtopping is produced. The functional form of the overtopping discharge rate under this condition is well described by a Weibull-type formula, which is the same formulation as for steep sloping structures (EurOtop, 2018, Van der Meer and Bruce, 2014). The existing literature of the overtopping research works in this regime primarily target at reducing the overtopping discharging rate, by using recurved parapets (Martinelli et al. 2018, Castellino et al., 2018) or still wave basin (Kisacik et al., 2019).

With regard to overtopping forces on structures, recently several papers have been published, which are primarily focused on the overtopping forces on 2-dimensional walls. Large-scale laboratory tests were performed by De Rouck et al. (2012) for breaking wave overtopping and impact on a storm wall. A so-called church-roof profile was reported for the recorded pressure and force on the wall, which shows a double-peaked force shape for a single impact event. Chen et al. (2015) further developed empirical formulas to predict the second peak of the church-roof profile force, which was called the quasi-steady force on the vertical wall. The derivation of the formula is based on the concept of depth-integrated momentum flux, and it is limited 


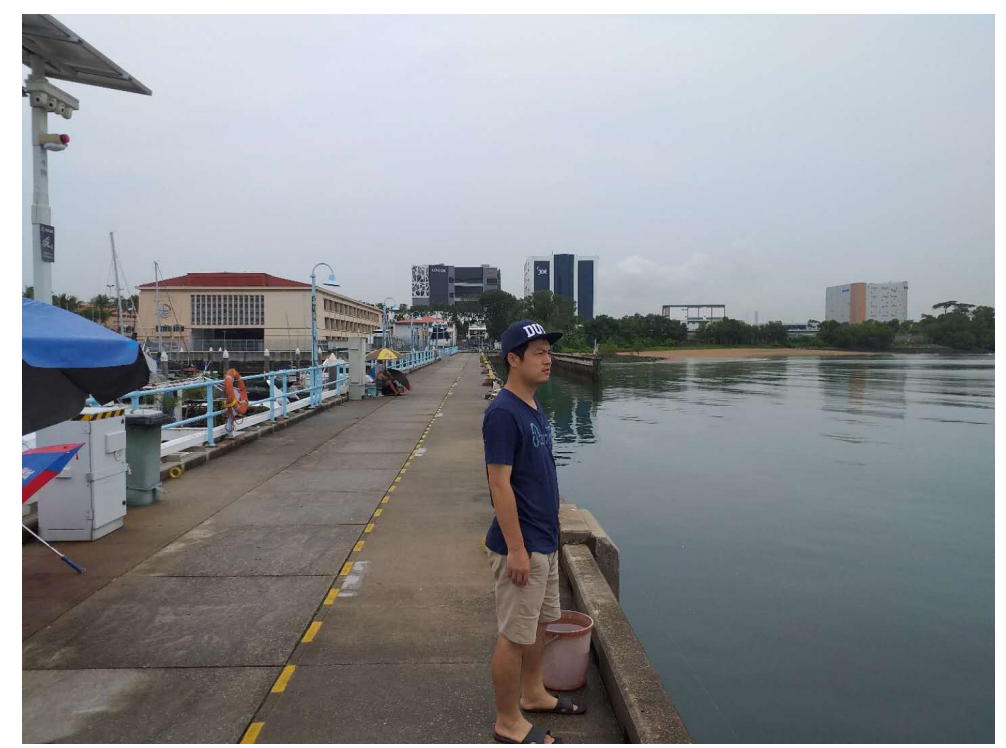

Figure 1: A vertical seawall at a marina in Singapore where the first author is standing.

to regular waves. Chen et al. (2016) conducted experiments under irregular wave conditions to estimate the maximum overtopping forces on the wall with a very shallow foreshore. An empirical Generalised Pareto distribution was verified as the best distribution for the extreme overtopping forces.

The human instability problem is considerably more complex than the common structural instability problems, which has been investigated by e.g. Arrighi et al. (2017); Endoh and Takahashi (1995); MartínezGomariz et al. (2016); Milanesi et al. (2015). It is commonly accepted that friction and moment instability are the major failure modes leading to human instability. Friction instability occurs when the driving flow force exceeds the stabilising force due to ground friction, while moment instability occurs if the overturning moment (with respect to a pivot point, i.e., the heel) is larger than the stabilising moment produced mainly by the body's weight. However, for overtopping force on human body, it is believed that the friction instability is the dominant failure mode as the overtopping flow has very small thickness and high speed (Jonkman and Penning-Rowsell, 2008). Therefore, the inline force, defined as the force in-line with the flow direction, is of interest in the present paper.

There are many factors that potentially affect the human stability in flooding water or overtopping flow, e.g., uncertainties in ground friction and pedestrian's response to incoming flow. These factors are not straightforward to be considered in a physical or numerical model. Instead, the human body is usually schematised as a fixed circular cylinder, of which the diameter is the representative width of human body. Such simplified representation of human body has been widely adopted in e.g. Lind et al. (2004), though many other factors such as the detailed geometry and the gaps between the feet are not considered. Particularly, in Endoh and Takahashi (1995), experiments were conduced to study the movement of human body 
subjected to overtopping waves at a vertical breakwater, which is mostly related to the present work in the published literature. Based on the critical water depth at the leading edge of the caisson and effects of other factors (e.g., hand railings), they proposed a set of empirical formulas to calculate the critical wave heights for splash, overtopping, a person to be knocked down and a person to be swept to the sea.

In the present paper, as described above, we are limited to investigate the non-impulsive wave overtopping forces on human body at a deep vertical seawall. The human body is schematised as a circular cylinder, and both physical and numerical models are used to investigate the non-breaking wave overtopping and its interaction process with the cylinder. Unlike a storm wall which can completely block the overtopping flow, in this case the overtopping flow is only locally deflected by the cylinder, and a wake is formed behind the cylinder. The physical quantities of most interest to us are the inline force on the cylinder, the overtopping flow depth and depth-averaged flow velocities, which are directly associated with the inline force. Meanwhile, the cylinder's location is also an important variable in this study, as overtopping flow thickness will decay as it transports landward due to friction force of the seawall crest.

The remaining of the paper is organised as follows. Section 2 presents a dimensional analysis for the maximum inline force on the cylinder, which can be used to justify the test conditions in the laboratory experiments. The physical and numerical models are described briefly in Section 3 and Section 4 respectively. The overtopping flow and the inline force from the numerical and experimental results are compared, and the effects of the cylinder's location are discussed in Section 5 Finally, an empirical predictor is developed in Section 6 for quick estimation of the maximum inline force on the cylinder at different locations, followed by the conclusions given in Section 7 .

\section{Dimensional Analysis}

This section presents a dimensional analysis for the maximum inline force on a cylinder located at the leading edge of the seawall, $F_{0 m}$, which is the key physical parameter for risk assessment. We must point out that in this study the $F_{0 m}$ is measured at $1.5 D$ from the actual leading edge, where $D$ is the diameter of the cylinder. This is because the exact leading edge is always unsafe (people can easily fall into the water), regardless of the overtopping flow, and usually some protective barrier is set to prevent people from reaching the exact leading edge. To account for the fact that $F_{0 m}$ increases with the cylinder's diameter $D$, the maximum inline force $F^{*}$ defined as $F^{*}=F_{0 m} / D$ is further introduced as the target variable. Apparently, $F^{*}$ depends on a set of variables as shown below

$$
\rho, \nu, g, H, T, R_{c}, D
$$

Here the wave condition is simply represented by the wave height $H$ and wave period $T$. The freeboard $R_{c}$ is the only variable for seawall design. The property of the fluid is described by the fluid density $\rho$ and 


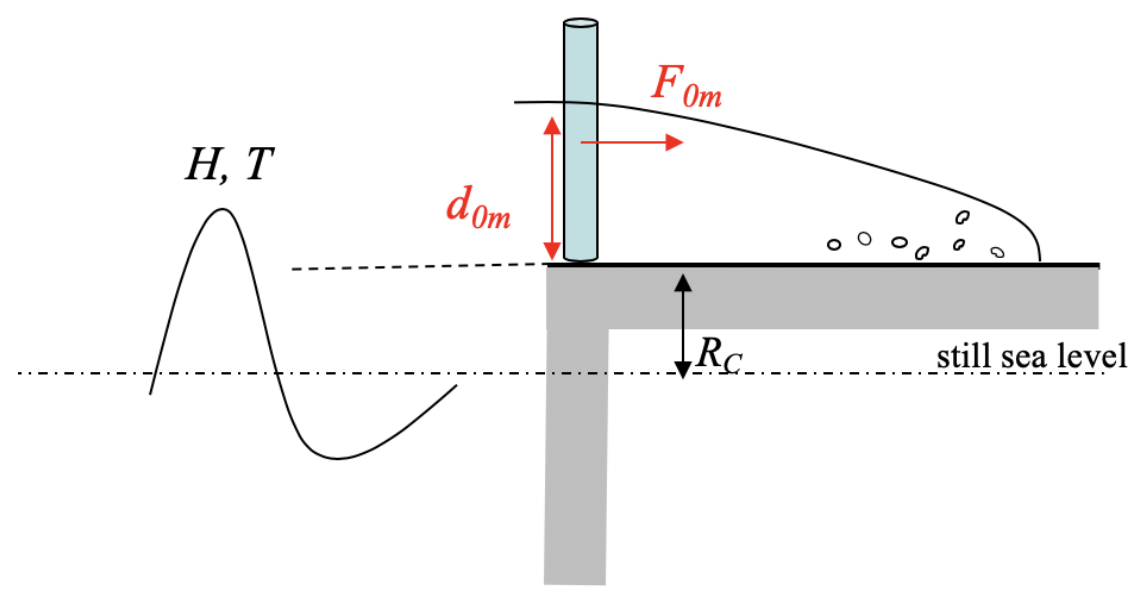

Figure 2: Definition of the physical quantities related to the maximum overtopping force.

the fluid kinematic viscosity $\nu$. The size of the cylinder is characterised by its diameter $D$. Finally, the gravitational acceleration $g$, is also a relevant variable. Fig. 2 provides a definition sketch for some of the variables.

This system has three fundamental dimensions, i.e., length, time and mass. Thus, the behaviour of the system is determined by five dimensionless terms. Here three variables $(H, g, \rho)$ are chosen as the dimensionally independent subset. The remaining independent variables and $F^{*}$ are converted into the following five dimensionless parameters:

$$
\Pi_{1}=\frac{F^{*}}{\rho g H^{2}} \quad \Pi_{2}=\frac{g T^{2}}{H} \quad \Pi_{3}=\frac{R_{c}}{H} \quad \Pi_{4}=\frac{\sqrt{g H^{3}}}{\nu} \quad \Pi_{5}=\frac{D}{H}
$$

$\Pi_{4}$ is a Reynolds number, which describes the role of viscous effect in the system. As will be discussed in section 5 , the inline force is due to a thin layer of high-speed flow striking on the cylinder, which is an inertia-dominant process. When the overtopping flow passes around the cylinder, the free surface elevation is decreased rapidly in the back side of the cylinder, which results in a very small immersed area in the back side of the cylinder. As $\Pi_{4}$ mainly controls the flow behaviour in the wake, it is expected that $\Pi_{4}$ should have an insignificant contribution to the total inline force on the cylinder. $\Pi_{5}$ compares the diameter of the cylinder to the incident wave height. For the background problem of overtopping flow striking on a human body, we are interested in the wave heights between $0.5 \mathrm{~m}$ and $1.5 \mathrm{~m}$, because this is a range with relatively large uncertainty. For very large waves, e.g., wave height exceeding $2 \mathrm{~m}$ combined with a mean overtopping discharge rate larger than $1 \mathrm{l} / \mathrm{s}$, it is not recommended for pedestrians to access seawalls' crest areas, as concluded in EurOtop (2018). Meanwhile, for wave heights smaller than $0.5 \mathrm{~m}$, the overtopping flow can hardly threaten pedestrians' safety. The equivalent diameter of the human body is within $20 \sim 40$ $\mathrm{cm}$. Thus, the variability of $\Pi_{5}$ is limited and it is assumed that $\Pi_{5}$ does not affect the system's behaviour. 


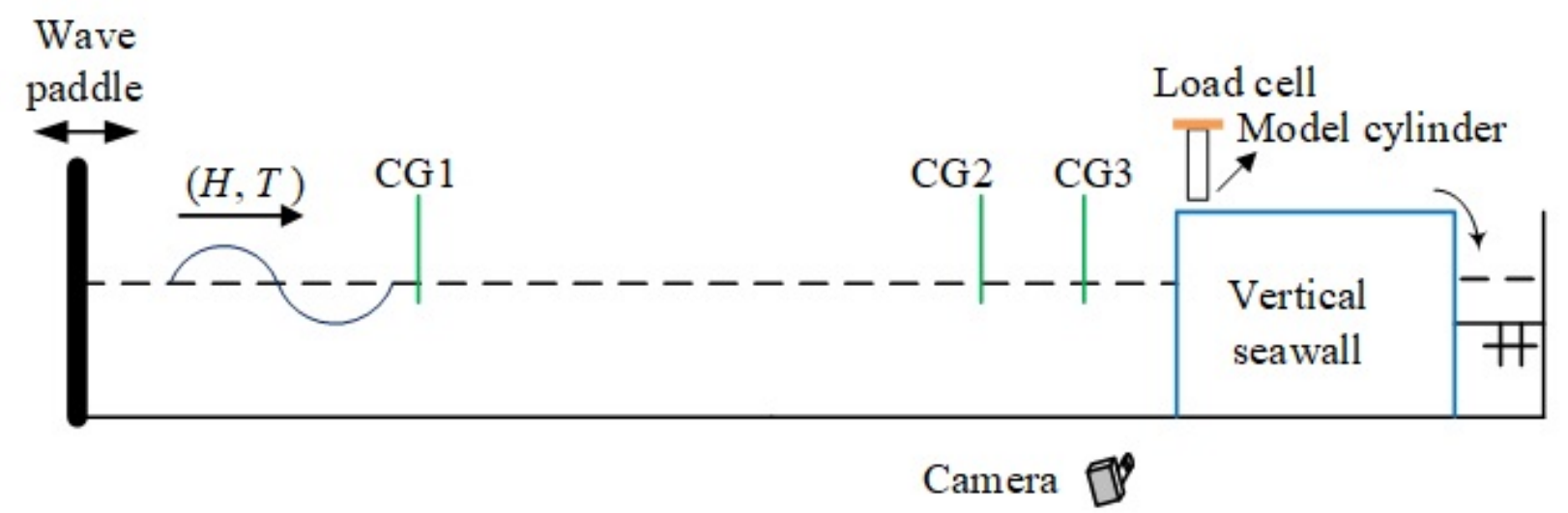

Figure 3: Sketch of the experimental setup in side view.

Hereby the dimensional analysis is reduced to

$$
\frac{F^{*}}{\rho g H^{2}}=f\left(\frac{H}{L_{0}}, \frac{R_{c}}{H}\right)
$$

which implicates that the maximum inline force depends on the wave steepness $H / L_{0}$, where $L_{0}=g T^{2} / 2 \pi$, and the relative freeboard $R_{c} / H$. This dimensional analysis also suggests that a geometrically-scaled laboratory experiments can be conducted to understand how $F^{*}$ varies with flow-seawall conditions.

\section{Experiments}

\subsection{Setup of the experiments}

Experiments were conducted in a wave flume in the Hydraulic Laboratory at National University of Singapore. The setup of the experiments is shown in Fig. 3. This wave flume is $36 \mathrm{~m}$ long, $1.3 \mathrm{~m}$ high and $2 \mathrm{~m}$ wide. A piston type wave-maker supplied by HR Wallingford is located at the left end of the flume, which can generate waves with a wave height of less than $20 \mathrm{~cm}$ in a water depth of $65 \sim 95 \mathrm{~cm}$. The target prototype wave height in this study is about $0.5 \sim 1.5 \mathrm{~m}$ (See Section 2). Thus, we set a geometrical scale of around 1:5. Near the right end of the flume, the side walls are made of glass, which ensures a clear observation of the flow from the side view. A vertical seawall model was installed at the right end of the flume at a distance of $26.57 \mathrm{~m}$ downstream from the wave-maker. A photo for the seawall model is presented in Fig. 4. The model was made by placing an aluminium vertical plate in front of the seawall crest, which was $1 \mathrm{~m}$ long and $1 \mathrm{~m}$ high.

A cylinder, as shown in Fig. 5 was placed on the model seawall crest as a surrogate of human body. The cylinder model was made of a plastic pipe with an outer diameter of $6 \mathrm{~cm}$, representing a human body width around $30 \mathrm{~cm}$ (assuming 1:5 scaling) at prototype scale. The upper end of the pipe was mounted to a three-axis force sensor, which was then fixed onto a rigid bar sitting on top of the side walls of the flume. 


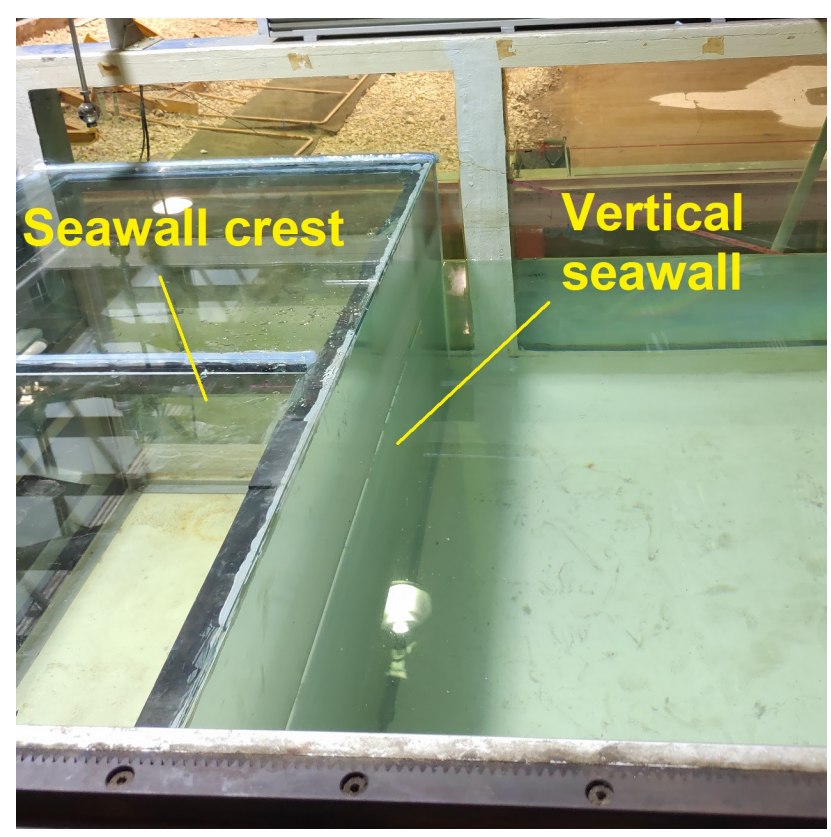

Figure 4: A photo of the vertical seawall model.

The cylinder was suspended by about $2 \mathrm{~mm}$ from the seawall surface. This tiny gap ensures that the cylinder did not touch the seawall surface during an experiment. Meanwhile, the bottom of the pipe was sealed to prevent overtopping flow from entering the pipe. The distance of the cylinder from the leading edge of the seawall's crest was varied to investigate the effect of the cylinder's location on the overtopping-flow-induced force.

\subsection{Measurement instruments}

The physical quantities measured in the experiments were: (a) free surface elevation in the flume; (b) depth of the overtopping flow on the seawall crest; (c) overtopping flow velocity; (d) inline force on the cylinder. For measurement of the surface elevation in the wave tank, three capacitance type wave gauges were installed at selected locations. These wave gauges were capable to measure a maximum wave height of $40 \mathrm{~cm}$ with an uncertainty of about $1 \mathrm{~mm}$. One gauge (named as CG1) was installed at $7.446 \mathrm{~m}$ downstream from the wave paddle to monitor the generated waves. Meanwhile, the incident wave height is obtained by conducting wave reflection analysis, based on the measurements of two wave gauges (CG2 and CG3) near the vertical seawall $(24.90 \mathrm{~m}$ and $25.33 \mathrm{~m}$ downstream of the wave-maker). As the wave-maker cannot perform active absorption function, we stop the experiment tests before re-reflected waves arrive at the seawall model.

In order to capture the wave overtopping process, a Sony high-speed camera with up to 100 frame per second was used, which can produce high-resolution figures of $1920 \times 1080$ pixels. Then the overtopping 


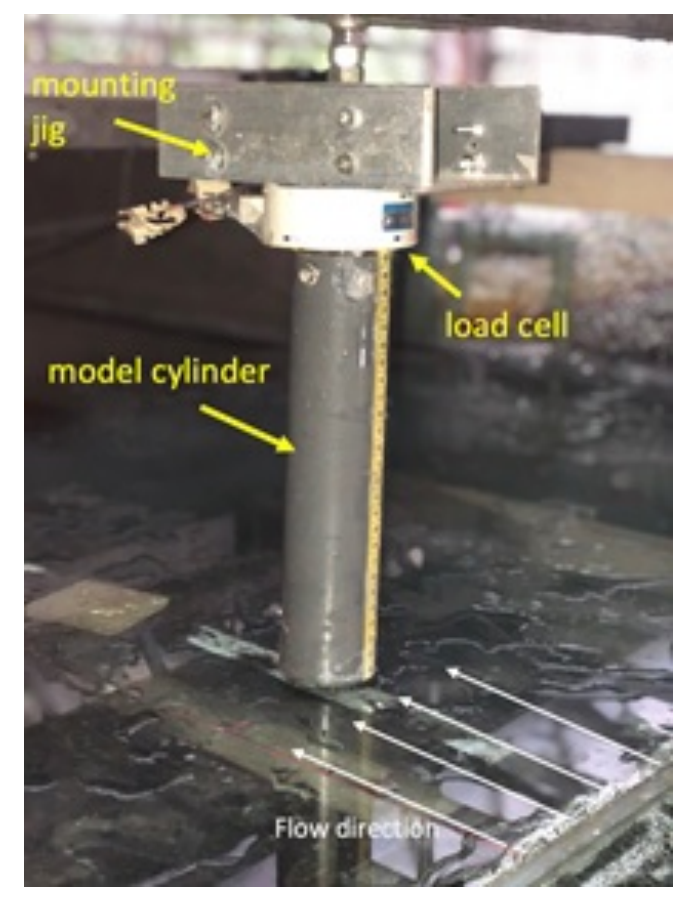

Figure 5: The cylinder used in the experiments as a surrogate of human body.

depths on the seawall crest were obtained by digitising the recorded videos. Regarding the overtopping flow velocity, it was measured using the Particle Image Velocimetry (PIV), which will be described in detail in Section 3.4. For measurement of the inline force on the cylinder, a three-component load cell (LSM-B-SA1, KYOWA) was deployed. It has a measuring capacity of $50 \mathrm{~N}$ and a natural frequency of $800 \mathrm{~Hz}$, and the measurement was sampled at a frequency of $200 \mathrm{~Hz}$. An 8-module (4 channels per module) National Instrument (NI) data acquisition system was used to synchronise the signals of wave gauges, ultrasonic probes and load cell. The captured videos were synchronised with all the other instruments by identifying the moment that the overtopping flow crosses the leading edge of the seawall crest for the first time.

\subsection{Test conditions}

Table 1 presents the key parameters of the current experiments and the corresponding full scale values assuming a model test scale of 1:5. Furthermore, selection of freeboard $R_{c}$ concerns the fact that the incident wave is mostly reflected by the seawall, leading to a standing wave in the wave flume. The seawall's front vertical surface is a node of the standing wave, so there is no overtopping flow if the freeboard $R_{c}$ is larger than the incident wave height. The wave height ranges between $0.15 \mathrm{~m}$ and $0.2 \mathrm{~m}$, so two values of freeboard, $0.1 \mathrm{~m}$ and $0.15 \mathrm{~m}$ were selected. The wave periods were $2-3$ seconds, corresponding to a wave period of 4.5 - 6.7 seconds in prototype. Totally five different cylinder's locations on the seawall crest were tested in the experiments to investigate the decay of the force on the cylinder. 
Table 1: Test matrix showing the ranges of the incident wave conditions and dimensions in the model and full scale, assuming a model test scale of $1: 5$.

\begin{tabular}{lccc}
\hline Description & Parameter & Model scale & Full scale \\
\hline Water depth & $h$ & $0.85-0.90 \mathrm{~m}$ & $4.25-4.50 \mathrm{~m}$ \\
Wave height & $H$ & $0.15-0.20 \mathrm{~m}$ & $0.75-1.00 \mathrm{~m}$ \\
Freeboard & $R_{c}$ & $0.10-0.15 \mathrm{~m}$ & $0.50-0.75 \mathrm{~m}$ \\
Wave period & $T$ & $2-3 \mathrm{~s}$ & $4.50-6.70 \mathrm{~s}$ \\
Cylinder location & $x_{c}$ & $0.09-0.50 \mathrm{~m}$ & $0.45-2.50 \mathrm{~m}$ \\
Cylinder diameter & $D$ & $0.06 \mathrm{~m}$ & $0.30 \mathrm{~m}$ \\
\hline
\end{tabular}

\subsection{Particle image velocimetry}

The inline force on the cylinder is strongly associated with the flow velocity, which was measured using a particle image velocimetry (PIV) system in the present experimental study. The PIV system mainly consists of a high speed camera and a laser, which is illustrated in Fig. 6. Due to the limited Field of View (FOV), the measurement was only conducted in the area between $x=-8.6 \mathrm{~cm}$ and $x=13.6 \mathrm{~cm}$, where $x=0$ corresponds to the seawall's leading edge.

The PIV system consists of an 8-W Diode Pumped Solid State (DPSS type) continuous laser with a wavelength of $532 \mathrm{~nm}$ as the light source and a high-speed camera. The beam emitted from the laser source was expanded by a cylindrical lens to form a 1-mm-thick laser sheet which was then cast downward into the water from the top of the flume. The flow was seeded with glass hollow spheres. The high-speed camera (Phantom Miro 340), which has 6 gigabyte memory storage, $2560 \times 1600$ pixel resolution, and a maximum frame rate of $800 \mathrm{~Hz}$, was used to capture images of the seeded flow. A $100 \mathrm{~mm}$ focal lens was mounted on the high-speed camera, which operated at 500 frames per second in the experiments. The velocity fields were determined by the cross-correlation analysis using a Matlab tool, i.e., PIVlab developed by Thielicke and Stamhuis (2014). A multigrid processing technique was adopted to enhance the accuracy of the velocity calculation. This multigrid process, which began and ended with $64 \times 64$ and $32 \times 32$ pixels, respectively, used interrogation windows with $50 \%$ overlap in the cross-correlation analysis.

\section{Numerical Model}

\subsection{Governing equations}

The governing equations of the numerical model include conservation equations of mass and momentum for an incompressible and immiscible two-phase flow system, where a volume of fluid (VoF) scheme is incorporated for tracking the free surface (Hirt and Nichols, 1981). In an Eulerian frame of reference, these 


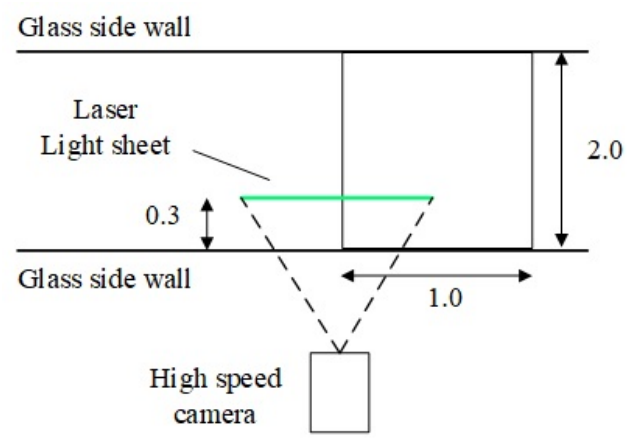

(a)

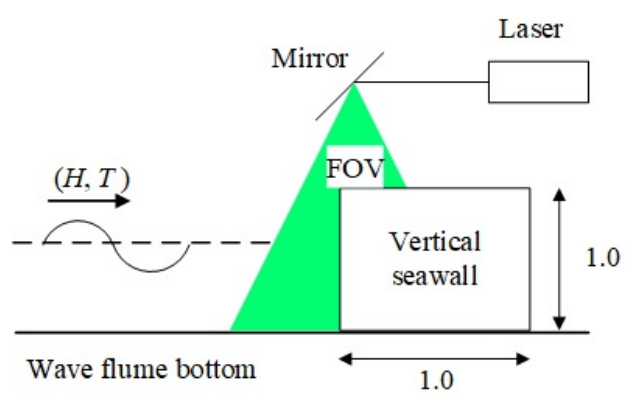

(b)

Figure 6: Sketch of the PIV setup for measurement of velocity: (a) top view; (b) side view (unit: m).

equations are given by

$$
\begin{gathered}
\frac{\partial u_{i}}{\partial x_{i}}=0 \\
\frac{\partial \rho u_{i}}{\partial t}+\frac{\partial \rho u_{i} u_{j}}{\partial x_{j}}=-\frac{\partial p}{\partial x_{i}}-g_{j} x_{j} \frac{\partial \rho}{\partial x_{i}}-\frac{\partial}{\partial x_{j}}\left(2 \mu S_{i j}+\tau_{i j}\right)+\sigma \kappa \frac{\partial \alpha}{\partial x_{i}}
\end{gathered}
$$

where $x_{i}$ is the Cartesian coordinate system, $u_{i}$ is the Reynolds averaged velocity component, $g_{i}$ is the gravity acceleration component, $\rho$ is the density, $p$ is the pressure in excess, $\mu$ is the dynamic viscosity and $\sigma$ is the surface tension coefficient. $\alpha$ is the water volume fraction and $\alpha \in[0,1]$. Thus, the volume fraction of air is given by the complementary fraction $1-\alpha . \kappa$ is the curvature of the interface which is calculated as

$$
\kappa=-\frac{\partial}{\partial x_{j}}\left(\frac{\partial \alpha / \partial x_{j}}{\left|\partial \alpha / \partial x_{j}\right|}\right)
$$

The last term on the right hand side of Eq. (4) is used to evaluate the surface tension force based on the continuum surface force model proposed by Brackbill et al. (1992).

In Eq. (4), the shear strain rate $S_{i j}$ is defined as

$$
S_{i j}=\frac{1}{2}\left(\frac{\partial u_{i}}{\partial x_{j}}+\frac{\partial u_{j}}{\partial x_{i}}\right)
$$


and the turbulent shear stress $\tau_{i j}$ is calculated according to the Boussinesq approximation

$$
\tau_{i j}=-\rho \overline{u_{i}^{\prime} u_{j}^{\prime}}=2 \mu_{T} S_{i j}+\frac{2}{3} k \delta_{i j}
$$

where the prime superscript denotes the fluctuating components. $k$ is the turbulent kinetic energy, $\delta_{i j}$ is the Kronecker delta, and $\mu_{T}$ is the eddy viscosity. A $k-\omega$ SST turbulence model was applied in the numerical model, which models the turbulent kinetic energy $k$ and the specific dissipation rate $\omega$. Then the eddy viscosity $\mu_{T}$ is obtained based on the computed $k$ and $\omega$.

The instantaneous local density and dynamic viscosity are specified in terms of the water volume fraction by the following constitutive equations

$$
\begin{aligned}
& \rho=\alpha \rho_{w}+\rho_{a}(1-\alpha) \\
& \mu=\alpha \mu_{w}+\mu_{a}(1-\alpha)
\end{aligned}
$$

where the subscript $w$ and $a$ refer to water and air, respectively. The isoAdvector approach proposed in Roenby et al. (2016) was adopted to advect the free surface, which is essentially an efficient two-step geometric VoF solver. In the first step, the free surface was explicitly reconstructed within each cell by applying the concept of isosurface. Secondly, from the reconstructed surface, the motion of the intersection lines between the cell face and the free surface was modelled to obtain their time evolution within a time step. Readers are referred to Roenby et al. (2016) for details of the algorithm.

\subsection{Computational domain and mesh}

The above introduced numerical model was applied to reproduce the experiments presented in Section 3 The waves were generated using the waves2Foam toolbox developed by Jacobsen et al. (2012). A relaxation zone was applied at the left side of the numerical wave tank to drive the waves according to the stream function wave theory. The relaxation zone was $5 \mathrm{~m}$ long, which was equivalent to $0.7 \mathrm{~L}$ to $1.1 \mathrm{~L}$ depending on the incident wave condition, where $L$ is the wave length. At the right side on the seawall crest, a short relaxation zone was utilized to absorb the overtopped flow. The cylinder was placed at different positions on the seawall's crest.

A structured multi-block mesh was generated using the native blockMesh toolbox, which is distributed with the OpenFOAM toolbox. In this problem, two distinct scales in the $x$ direction appear to be important. In the wave-making zone, the grid only needs to properly resolve the large-scale wave propagation, but on the seawall's crest, the scale of the local flow around the cylinder is in the order of millimetre. Similarly, in the lateral direction, the flow is largely 2-dimensional until the overtopping flow encounters the cylinder. Therefore, the mesh was largely squeezed nearly the cylinder to ensure a sufficient resolution for the complex local flow around it. Totally 17 blocks were used within the domain and an overview of the computational mesh is presented in Fig. 7 with the local mesh structures around the cylinder. 


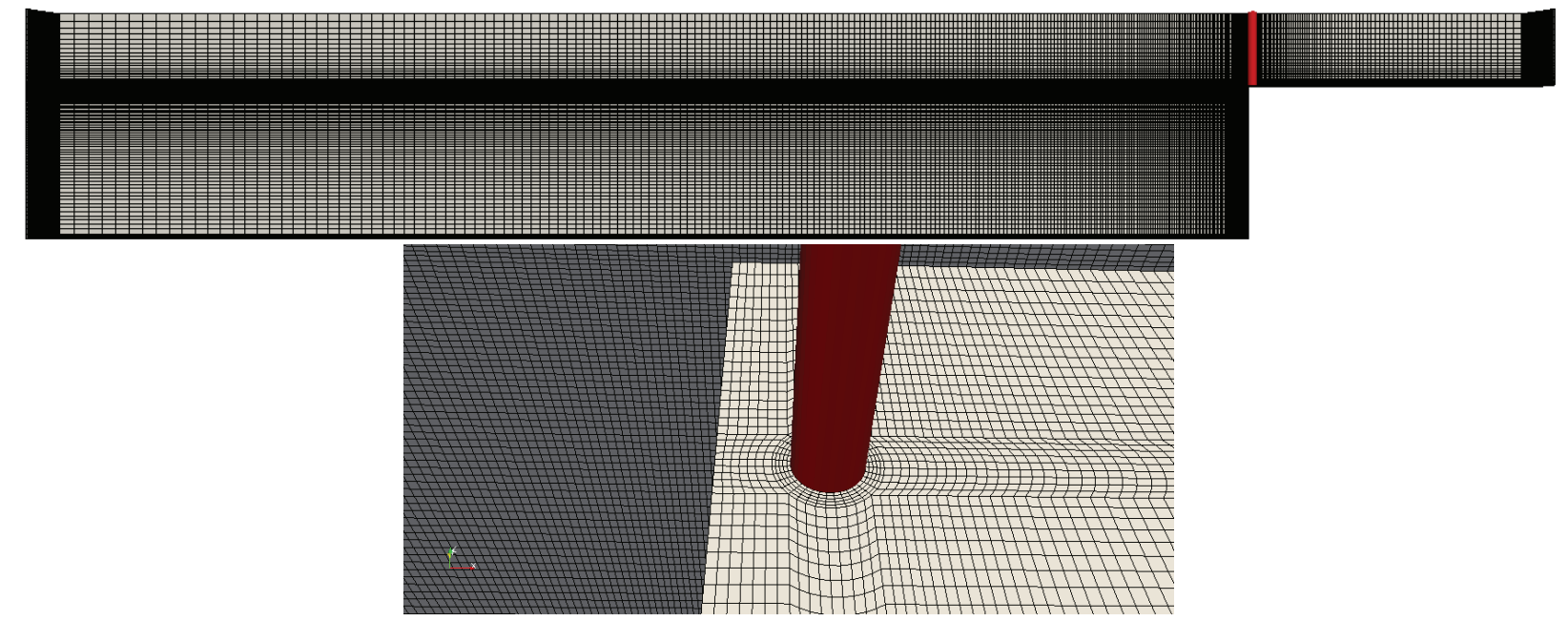

Figure 7: Example of the structured multi-block mesh. Upper: an overview of the mesh, where the cylinder is highlighted by the red colour. Lower: The mesh in the vicinity of the cylinder. For this illustration, the total mesh number is $0.85 \times 10^{6}$, corresponding to the Grid 1 as shown in Table 2

\subsection{Convergence analysis}

A convergence test was performed to verify the sensitivity of the inline force on the grid resolutions, since a relatively high resolution was required to properly resolve the flow near the cylinder. The convergence test was performed for the case with $H=0.185 \mathrm{~m}, T=3 \mathrm{~s}$ and $R_{c}=0.1 \mathrm{~m}$. Four different grid resolutions were tested, and the relevant parameters are given in Table 2. These four different grids are geometrically similar, and the total number of grid ranges from less than one million to more than four millions. Further analysis shows that for the grid resolution in the wave-making zone, the resolution ranges between $H / \Delta z=46 \sim 80$ vertically, and $L / \Delta x=157 \sim 272$ horizontally. Generally speaking, such resolutions are sufficiently fine for wave-making problems. Near the cylinder, the maximum overtopping flow depth for this case is about 0.07 $\mathrm{m}$, so the overtopping flow depth is resolved by $17 \sim 30$ cells vertically. Therefore, the main behaviour of the overtopping flow is expected to be correctly resolved by these grids.

However, the boundary layer of the overtopping flow on the seawall's crest and around the cylinder cannot be correctly resolved by all of the four grids. The boundary layer thickness can be roughly estimated using the flat plate theory. Given a characteristic velocity of $0.8 \mathrm{~m} / \mathrm{s}$ for the overtopping flow in this test, at $0.5 \mathrm{~m}$ away from the leading edge of the seawall, the boundary layer has a thickness of $4 \mathrm{~mm}$, i.e., similar as the vertical length of the first layer of grid. In the present study, a wall function was applied to help describe the flow inside the boundary layer. However, it is not guaranteed that the boundary layer is adequately modelled even with the aid of a wall function. In Section 5 it is shown that the important effects are gravity and inertia, while viscous effect is secondary. This can also be demonstrated by the results of the convergence test. Fig. 8 presents one cycle of the inline force using these four different grids. It is 
Table 2: Mesh parameters for the convergence study. The cell size in the wave-making zone is the averaged size at the free surface area, as there is a smooth refinement from the far end near the wave-maker boundary to the area near the seawall. The cell size in the near-cylinder zone is the size of the first layer cell above the seawall's crest near the cylinder.

\begin{tabular}{ccccccc}
\hline \multirow{2}{*}{ Grid NO. } & \multicolumn{2}{c}{ Wave-Making Region } & \multicolumn{3}{c}{ Near-Cylinder Region } & Mesh NO. [million] \\
& $\Delta x[\mathrm{~mm}]$ & $\Delta z[\mathrm{~mm}]$ & $\Delta x[\mathrm{~mm}]$ & $\Delta y[\mathrm{~mm}]$ & $\Delta z[\mathrm{~mm}]$ & \\
\hline 1 & 38 & 4.0 & 6.0 & 6.0 & 4.0 & 0.85 \\
2 & 30 & 3.4 & 5.0 & 5.0 & 3.4 & 1.81 \\
3 & 26 & 2.8 & 4.2 & 4.2 & 2.8 & 2.64 \\
4 & 22 & 2.3 & 3.5 & 3.5 & 2.3 & 4.60 \\
\hline
\end{tabular}

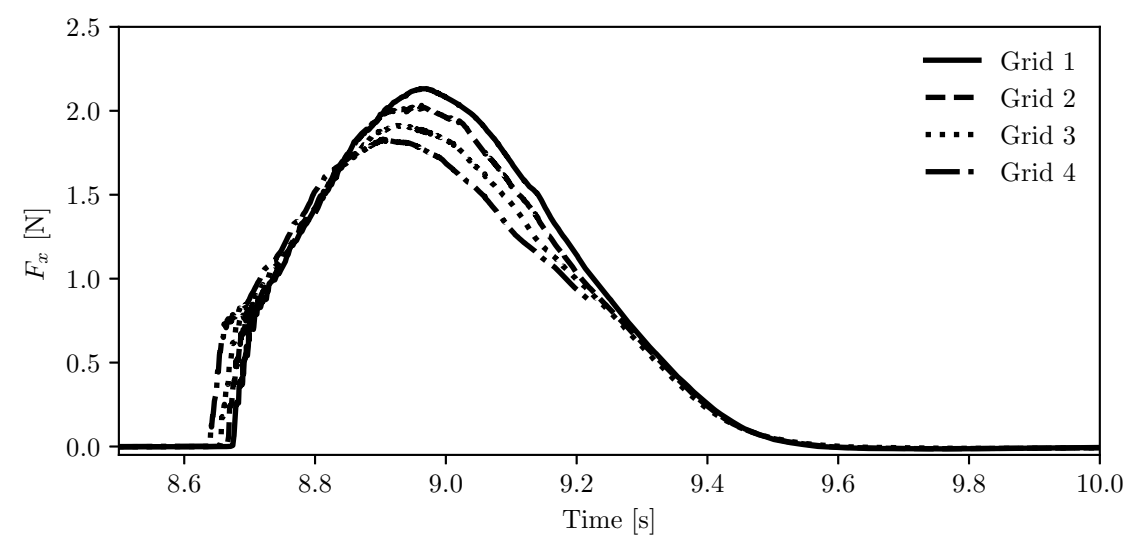

Figure 8: Computed inline force on the cylinder during one overtopping event using different grid resolutions. The relevant parameters for the grid resolutions are shown in Table 2. The condition for the test is $H=0.185 \mathrm{~m}, T=3 \mathrm{~s}, h=0.9 \mathrm{~m}$ and $R_{c}=0.1 \mathrm{~m}$.

found that the four force curves have similar shape with a single peak in each overtopping event. The main difference is on the magnitude of the peak value. A clear trend is that by increasing the resolution, the numerical result converges to a smaller peak. The occurrence time of the peak is likely to be earlier with finer mesh. However, the difference between two consecutive mesh grids reduces and the relative discrepancy is around 3\% between Grid 3 and Grid 4, which can be considered negligible. Hence, Grid 3 is applied for all the simulations in the following discussions. This also shows that a nearly convergent inline force can be obtained without fully resolving the boundary layer, indicating the secondary importance of viscous effects in our applications. 


\section{Results and discussion}

\subsection{Overtopping flow process}

Overtopping flow is initialised when the free surface at the vertical seawall boundary is elevated higher than the height of the seawall. The free surface of the overtopping flow remains very smooth over the whole process. Therefore, the Particle Image Velocimetry (PIV) measurements were conducted, which are compared with the 2-dimensional numerical results.

Fig. 9 presents the snapshots since the beginning of an overtopping event. The subfigures in the left column is the PIV images of the instantaneous flow. The horizontal velocity, $u$, of the PIV measurements is shown in the middle column, and the corresponding numerical simulation is provided in the right column. At the very beginning of the overtopping event, water is spilled onto the seawall's crest since the water level in front of the seawall exceeds the crest level. A small rounded jet is formed at the front of the flow, which plunges directly onto the seawall's crest. As a consequence, a cavity is formed with air trapped inside and the scale of the cavity is around $1 \sim 2 \mathrm{~cm}$ in this test. This behaviour is very similar to the case of green water on deck, which has been reported in Greco et al. (2005). In the experiments, it is observed that the cavity is further advected by the overtopping flow, and breaks into smaller bubbles. The horizontal velocity at the leading edge of the seawall is generally low, since the flow motion is mainly in the vertical direction in front of the seawall. The depth of the overtopping flow decreases while the velocity increases along the inland direction. This suggests that the kinetic energy of the overtopping flow mainly comes from the flow's potential energy at the leading edge.

From Fig. 9, it is shown that qualitatively the free surface profile and the flow velocity are well reproduced by the numerical model. In addition, it also successfully predicts the formation of the cavity. Both the initial size and the location of the cavity are adequately simulated. However, the model fails to simulate the evolution of the cavity, including its breaking into small bubbles. Actually, one needs to correctly model the viscous and surface tension effects on the bubble, in order to reproduce its deformation and breakup (Chu et al. 2019, Liao and Lucas, 2009). However, this cannot be achieved by the present model due to the coarse resolution in regard to the bubble size. Furthermore, the numerical model is based on the incompressible fluid flow (see Eqs. (3-4)). Hereby the air within the cavity cannot be compressed in the numerical model, which also leads to the discrepancy. Nevertheless, the evolution of the cavity itself has little effect on the inline force on the cylinder, which will be demonstrated in Section 5.2. It is the bulk behaviour of the overtopping flow, e.g., the overtopping flow depth and the depth-averaged velocity that determine the inline force on the cylinder.

Fig. 10 presents the detailed comparison of the instantaneous inline velocity profile between the PIV measurements and the numerical simulations. The agreement is generally good except close to the bottom. The flow is very complex in that small area where the dynamics of the cavity affects the velocity distribution. 

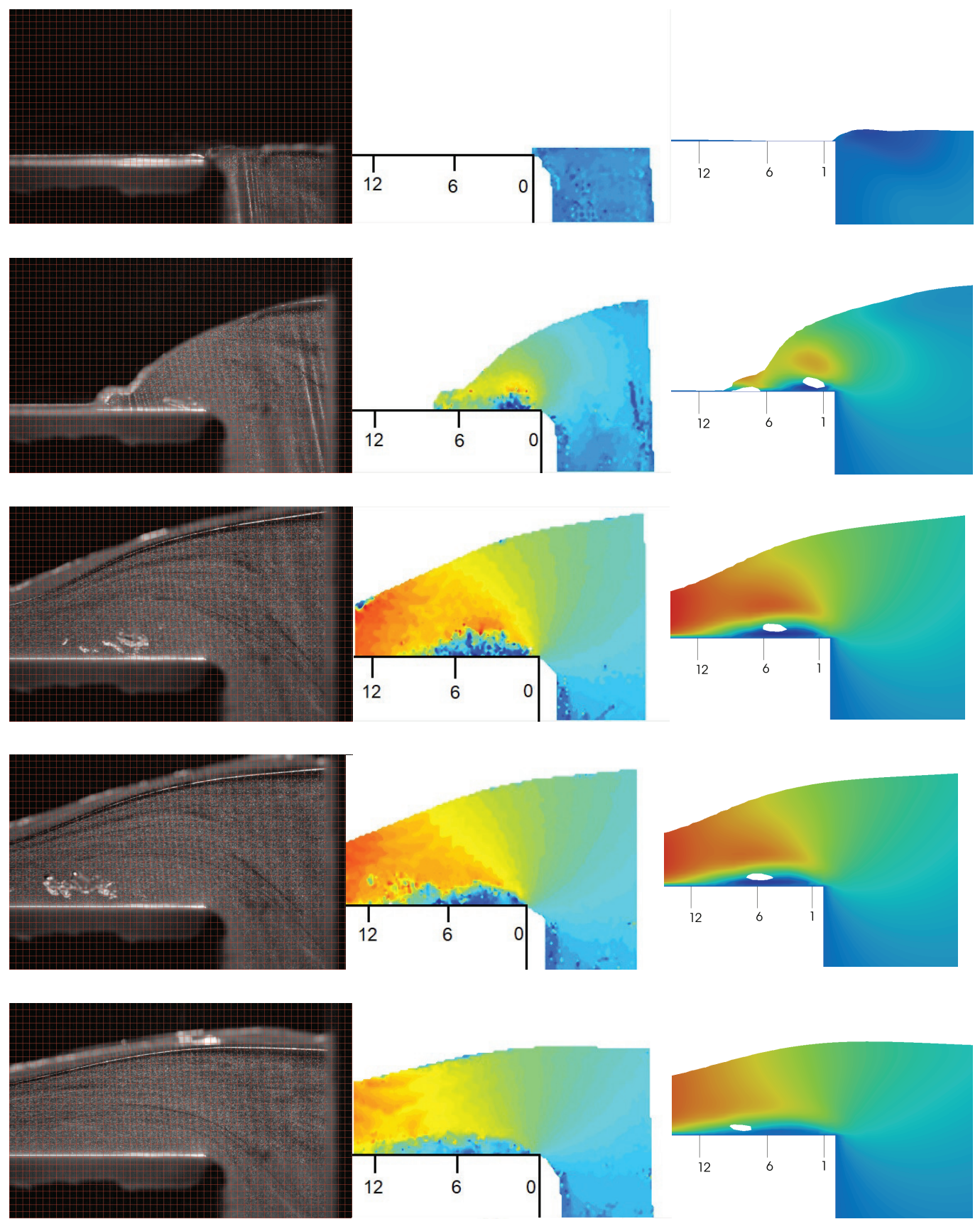

Ux

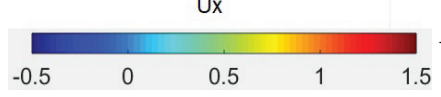

$-0.50 \quad 000.4 \quad 0.8 \quad 1.2 \quad 1.50$

Figure 9: Left: Snapshots of the overtopping flow on the seawall during one overtopping event (the condition is $H=0.185 \mathrm{~m}$, $T=3 \mathrm{~s}, h=0.9 \mathrm{~m}$ and $R_{c}=0.1 \mathrm{~m}$ ). The reference time of $t=0 \mathrm{~s}$ is when the flow is elevated in the same level as the seawall. From upper to lower, the occurrence time are $t=0.01 \mathrm{~s}, t=0.16 \mathrm{~s}, t=0.41 \mathrm{~s}, t=0.47 \mathrm{~s}$ and $t=0.59 \mathrm{~s}$. The cell size for the grid in the left column of the figures is $4.37 \times 4.53 \mathrm{~mm}$. Middle: The inline velocity contour at the corresponding time instant from PIV images. Right: The inline velocity contour at the corresponding time instant from the numerical simulations. 
Negative velocity is observed below the air cavity at e.g., $t=0.41 \mathrm{~s}$, which is primarily due to the cavity motion. As air-water interaction cannot be fully reproduced by the numerical model, there appear to be some discrepancies regarding the velocity distribution near the air cavity. However, such discrepancies are confined within a small area comparing with the scale of the overtopping flow depth, and the deviation of the velocity distribution within it is trivial to the inline force on the cylinder. Again we emphasise that it is the depth-averaged flow velocity that is important to the inline force. From the comparison, it is shown that this can be reasonably estimated by the numerical model.

When overtopping flow further travels inland, it is expected that the flow should decay along its journey. Fig. 11 presents the comparison of the overtopping flow depth at various locations between the numerical and experimental data. We observe a slight overestimation of the flow depths by the numerical model at all the four locations, and the maximum difference occurring at the peak ranges from $4.2 \%$ to $9.3 \%$. A clear decay of the overtopping flow depth is depicted by both the experimental and the numerical results. Fig. 12 further depicts the decay of the maximum overtopping flow depth along the seawall under a variety of wave conditions. Here we use the maximum overtopping depth at the seawall's leading edge, $d_{0 m}$, to normalise the $x$ coordinate and the local maximum overtopping depth $d_{m}$. The data were collected from both numerical simulations and experiments. For nearly all the cases, a dramatic drop of flow depth is found within the region of $x / d_{0 m}<5$, where the maximum depth of the overtopping flow reduces to less than half of the maximum depth at the leading edge of the seawall. As can be seen from the example in Fig. 9 the flow depth near the seawall's leading edge indeed drops quickly, since locally the flow's potential energy is rapidly converted into its kinetic energy. Beyond $x / d_{0 m}=5$, the depth reduces much more slowly and seems to become rather invariant. In this region, the overtopping flow becomes a thin layer of high-speed flow, which is similar to the overtopping flow over a sloped revetment.

Another important quantity that determines the force on the cylinder is the depth-averaged velocity, which is primarily obtained from the numerical model. The variation of the depth-averaged velocity is completely different from that of the overtopping flow depth. Fig. 13 shows the variation of the normalised local maximum depth-averaged flow velocity $U_{m} / U_{0 m}$ with the normalised $x$ coordinate, $x / d_{0 m}$, where $U_{m}$ is the local maximum depth-averaged velocity and $U_{0 m}$ is the maximum depth-averaged velocity at the leading edge of the seawall crest. There is a rapid increase of $U_{m} / U_{0 m}$ from the leading edge to approximately $x / d_{0 m}=5$, where $U_{m} / U_{0 m}$ grows to about 2. Within $5<x / d_{0 m}<12, U_{m} / U_{0 m}$ seems to be unchanged. The increase of the maximum flow velocity is associated with the conversion of flow's potential energy to kinetic energy. From $x / d_{0 m}>12, U_{m} / U_{0 m}$ gradually decreases, which mainly because of energy dissipation due to viscous effect (e.g. bottom friction). Actually, this has a similarity with dam-break flow, which has been taken as a surrogate of wave overtopping flow (Hu et al., 2015, Zhang et al., 2019, Ryu et al., 2007). 

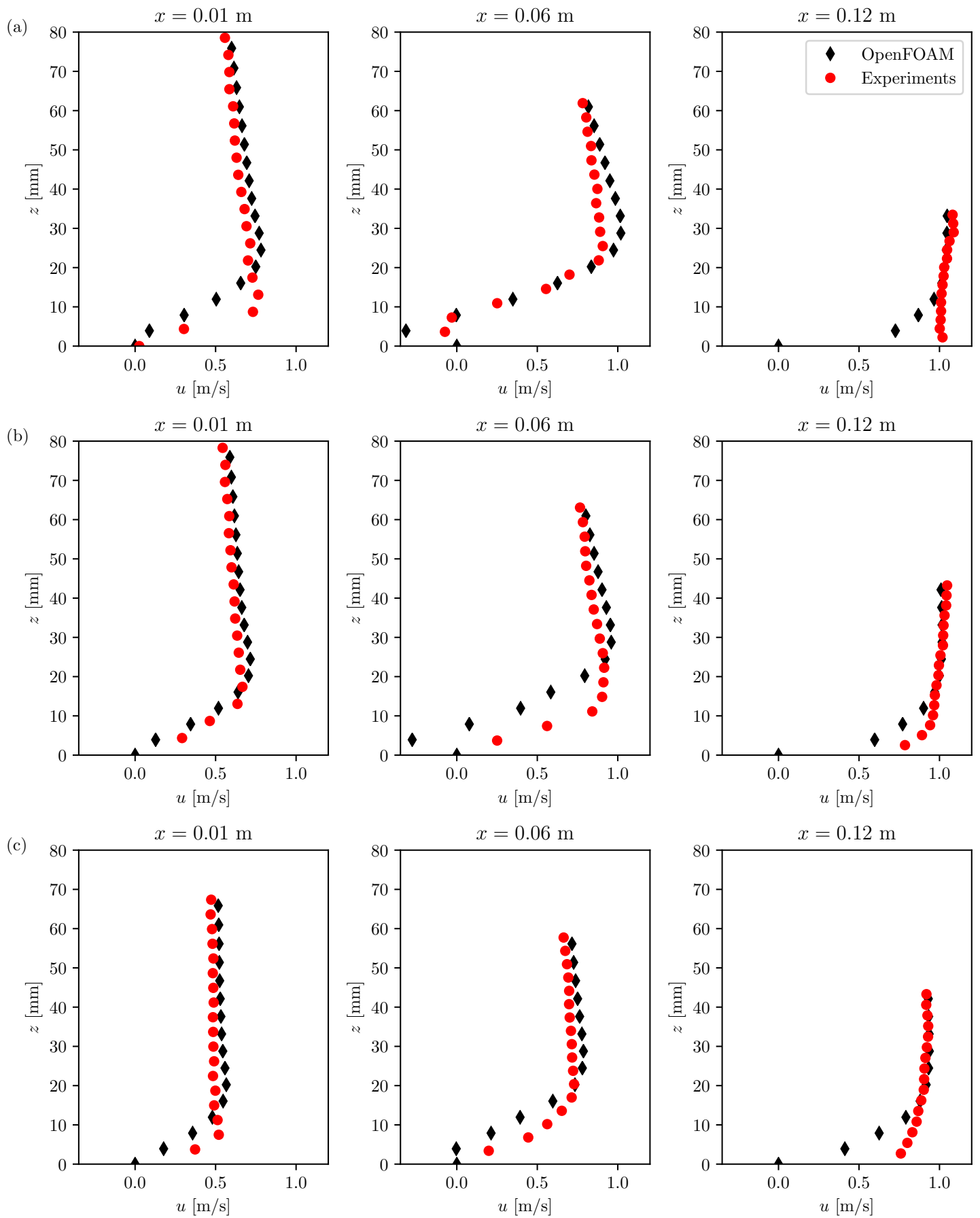

Figure 10: Comparison of the $x$ component of the velocity profile at three cross sections $x=0.01 \mathrm{~m}, x=0.06 \mathrm{~m}$ and $x=0.12$ $\mathrm{m}$ at different time instants under the same wave condition as in Fig. 9 . (a) $t=0.41 \mathrm{~s}$. (b) $t=0.47 \mathrm{~s}$. (c) $t=0.59 \mathrm{~s}$. The overtopping event starts at $t=0$ when the flow at the seawall is elevated at the same level with the seawall height. 

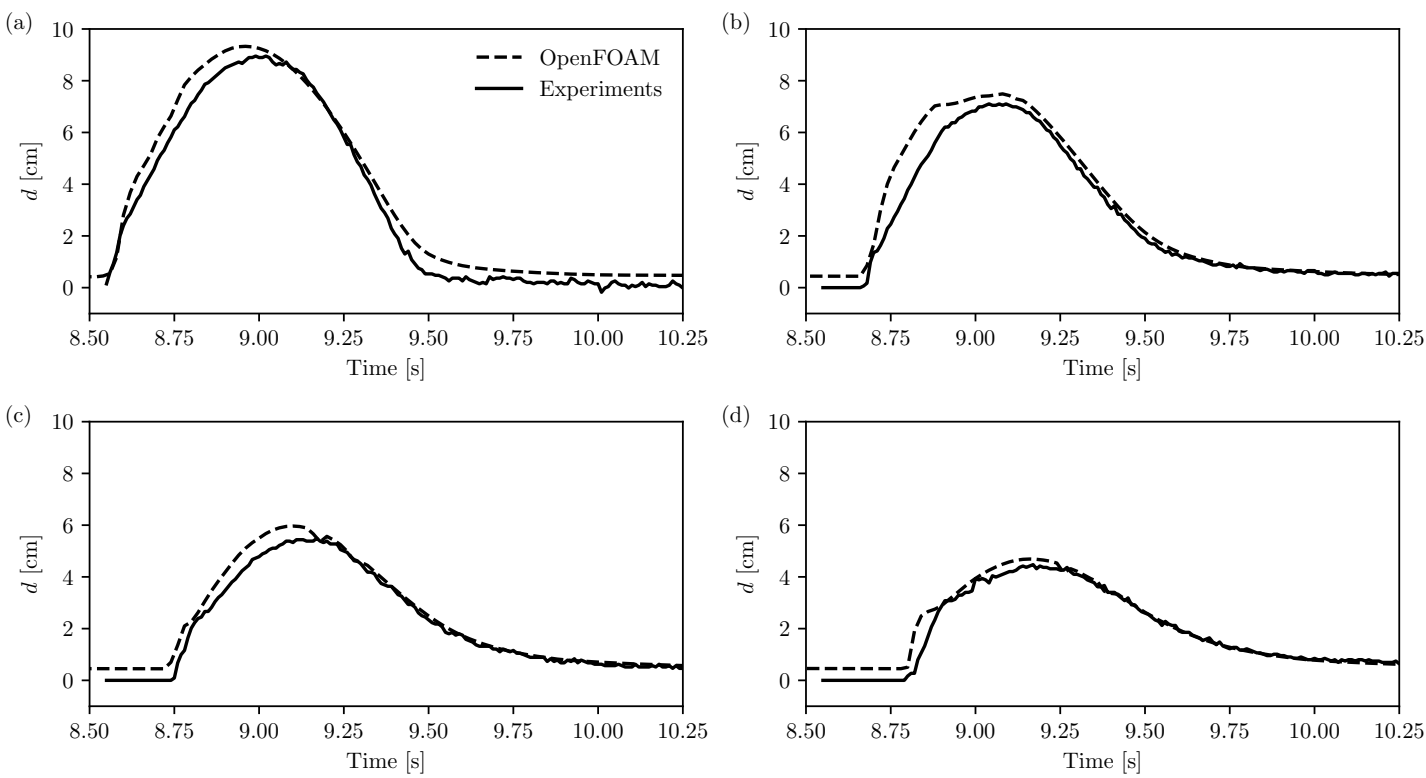

Figure 11: Comparison of the time series of the overtopping flow depth at different positions on the seawall's crest under the same wave condition as in Fig. 9. (a) $x=0 \mathrm{~m}$. (b) $x=0.06 \mathrm{~m}$. (c) $x=0.12 \mathrm{~m}$. (d) $x=0.18 \mathrm{~m}$. The time shown in the $x$ axis is based on the numerical simulations. The flow depth from the experiments is extracted by digitalising the PIV images.

\subsection{Overtopping flow interaction with cylinder}

The overtopping flow is largely 2-dimensional before it encounters the vertical cylinder. Then the overtopping flow is locally deflected and becomes 3-dimensional, and an inline force is induced by the overtopping flow. Fig. 14 presents the comparison of the inline force between the numerical simulations and the experiments during one overtopping event. The peak magnitude is precisely predicted by the numerical model, although the occurrence time is slightly shifted. The total inline force on the cylinder is the summation of the integration of pressure and viscous shear stress. The former one is usually called the form drag while the latter one is the friction drag. During the interaction between the overtopping flow and the cylinder, it is found that the form drag is the dominant source of inline force, while the friction drag is less than $2 \%$ of the total force during the whole event. This is also shown in Fig. 14 and it is consistent for all the incident wave conditions.

The analysis on the detailed interaction process between the overtopping flow and the cylinder is presented below, which is largely based on the numerical results. Fig. 15 presents snapshots of the local flow and velocity near the cylinder, and the pressure distribution around the cylinder before and after the occurrence of the maximum inline force. It is clearly observed that the instantaneous free surface is elevated in the front of the cylinder. Meanwhile, a local runup jet flow is formed and climbs along the front stagnation line of the cylinder. Along both sides, the surface elevation is dropped considerably, as demonstrated by the white 


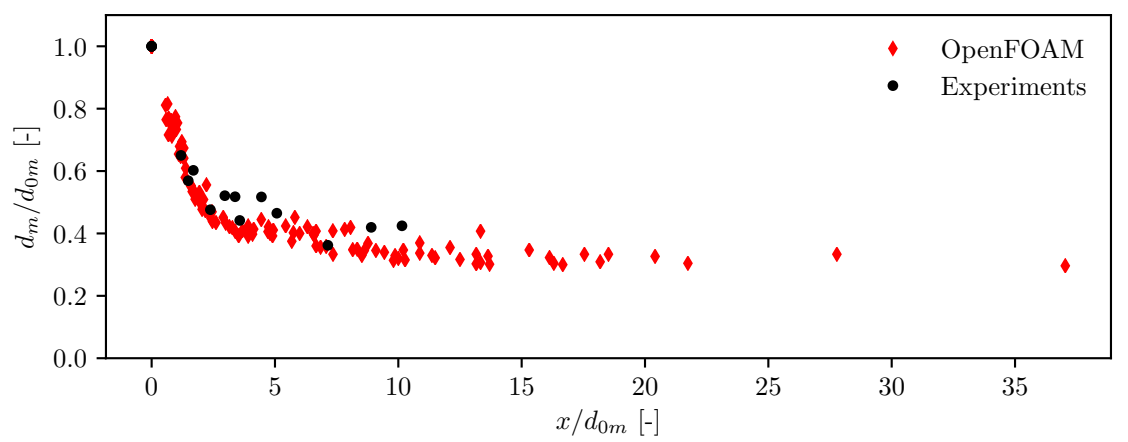

Figure 12: Decay of the nondimensional maximum overtopping flow depth $d_{m} / d_{0 m}$ along the seawall's crest. $x=0$ is at the leading edge of the seawall's crest. $d_{0 m}$ corresponds to the maximum overtopping flow depth at the leading edge.

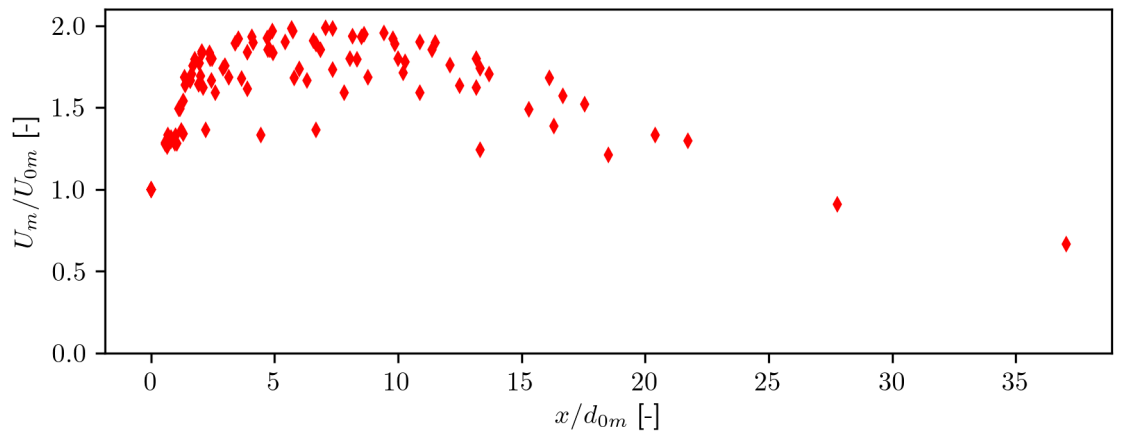

Figure 13: Variation of the nondimensional maximum depth-averaged velocity $U_{m} / U_{m 0}$ along the seawall's crest. All the data are extracted from the numerical simulations. $x=0$ is at the leading edge of the seawall's crest. $d_{0 m}$ corresponds to the maximum overtopping flow depth at the leading edge and $U_{0 m}$ corresponds to the maximum depth-averaged velocity at the leading edge.

lines denoting the free surface in the sub-figures in the second and third columns of Fig. 15. Eventually, at the back of the cylinder, the flow from both sides merges together, which results in a rear runup flow and a complex wake behind the cylinder. This runup flow is significantly smaller than the runup in the front of the cylinder. Such variation of free surface around the cylinder has been reported in other publications e.g. Kristiansen and Faltinsen (2017), Paulsen et al. (2014).

A further quantitative examination on the pressure distribution around the cylinder is presented in Fig. [16- 17. Fig. 16 presents the pressure along the front and back stagnation lines of the cylinder. Initially, when the flow just starts to interact with the cylinder at $t=8.7 \mathrm{~s}$, the pressure distribution is strongly non-hydrostatic. The pressure is likely to be uniformly distributed between $z=0.01 \sim 0.03 \mathrm{~m}$. However, it rapidly evolves to a nearly hydrostatic distribution later from $t=9.0 \mathrm{~s}$. Along the back stagnation line, due to the complex wake effects, the pressure looks much smaller and it has a more irregular vertical variation than the pressure along the front stagnation line. Such a pressure distribution strongly indicates that the 


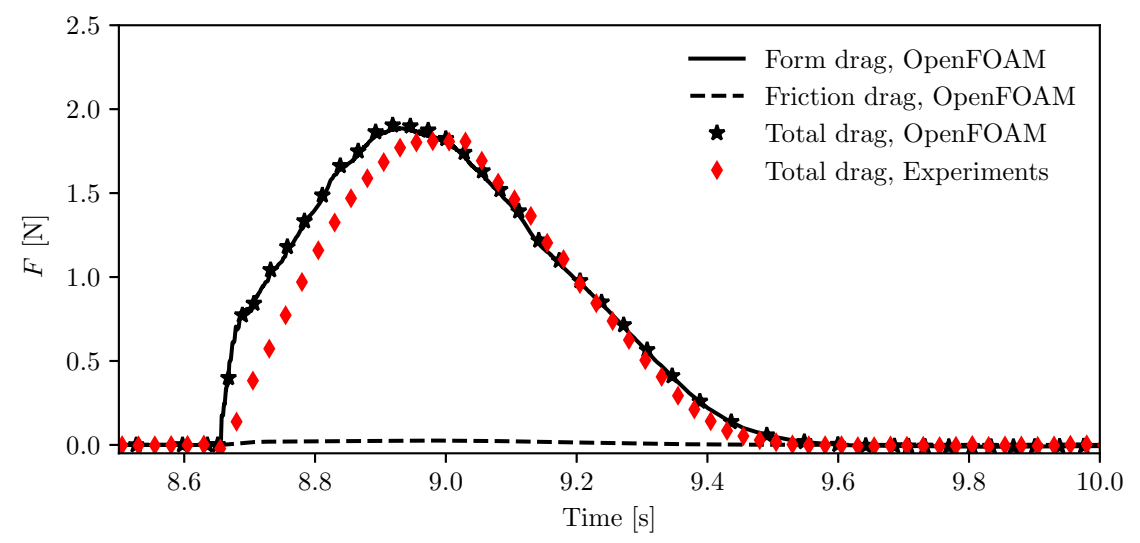

Figure 14: Comparison between the form drag and the friction drag during one overtopping event. The form drag and friction drag are extracted from the numerical simulations. The total drag force from the experiments and numerical simulations are also presented for reference. The incident wave condition is $H=0.185 \mathrm{~m}, T=3 \mathrm{~s}, h=0.9 \mathrm{~m}$ and $R_{c}=0.1 \mathrm{~m}$.

inline force is due to the difference of the pressure acting on the front and the back sides of the cylinder. This is further confirmed in Fig. 17, which presents the vertical line integration of the pressure from the bottom to the instantaneous free surface position. The pressure integration for the front side, i.e., $-45^{\circ}<\phi<45^{\circ}$ is considerably larger than that for the back side. It starts to increase when the flow begins to touch the cylinder and reaches the maximum between $t=8.85 \mathrm{~s}$ and $t=9.0 \mathrm{~s}$. Then its magnitude is reduced in the following time instants until one overtopping event ends. Meanwhile, the pressure integration for the back side of the cylinder continues to increase between $t=8.70 \mathrm{~s}$ and $t=9.15 \mathrm{~s}$, which counteracts the pressure integration in the front side. As shown in Fig. 17, at $t=9.0 \mathrm{~s}$, the cylinder has a larger pressure integration on the front side than at $t=8.85 \mathrm{~s}$, but it also has a large pressure integration on the back side. Thus, these two time instants have almost identical inline force, and the peak inline force occurs between $t=8.85$ $\mathrm{s}$ and $9.0 \mathrm{~s}$.

When the cylinder moves further inland, the inline force on the cylinder varies with the distance to the leading edge of the seawall, i.e. $x_{c}$. Fig. 18 presents an example of the time series of the overtopping flow depth and the inline force on the cylinder at various $x_{c}$. There are several characteristics that should be paid attention to. Firstly, with the increase of $x_{c}$, both the flow depth and the force become more and more asymmetric with regard to the maximum value, i.e., a rapid rising followed by a slow decay. This is because the overtopping flow evolves into a bore-like flow as it moves inland, of which the tip has larger depth and velocity than the tail. Furthermore, apparently with the increase of $x_{c}$, the maximum inline force drops much slower than the maximum depth of the overtopping flow. Comparing Fig. 18 a and Fig. 18 c, it can be seen that at $x_{c}=0.39 \mathrm{~m}$ the maximum force is reduced by about $25 \%$ while the maximum flow depth $d_{m}$ is reduced by $50 \%$. This is primarily because that the flow velocity increases with $x_{c}$ within $x_{c} / d_{0 m}<5-10$, as shown in Fig. 13. The maximum inline force is scaled with $d_{m} U_{m}^{2}$ where $d_{m}$ is the local maximum flow 
(a)
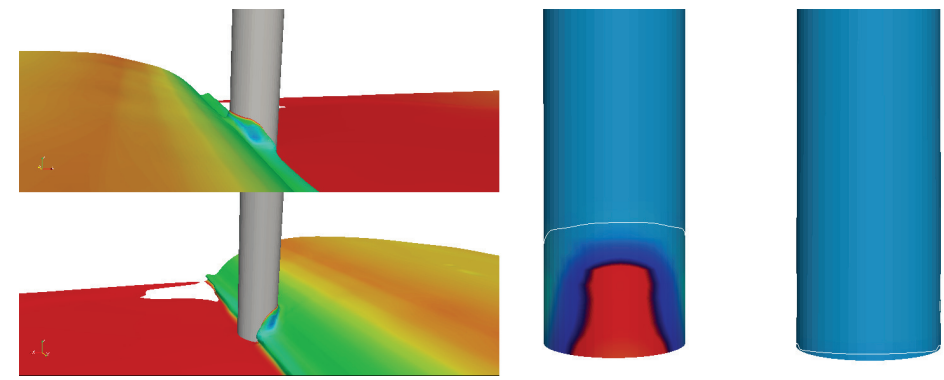

(b)
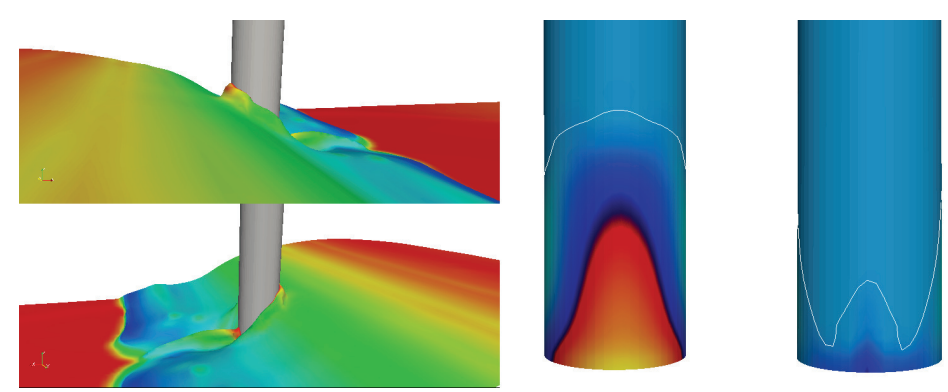

(c)
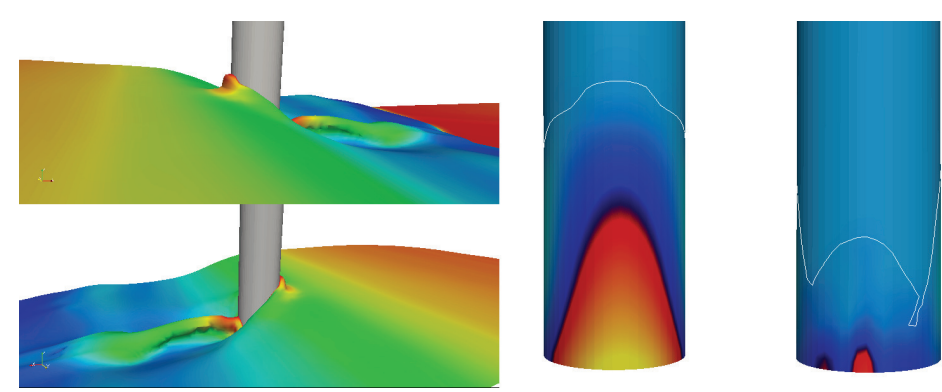

(d)

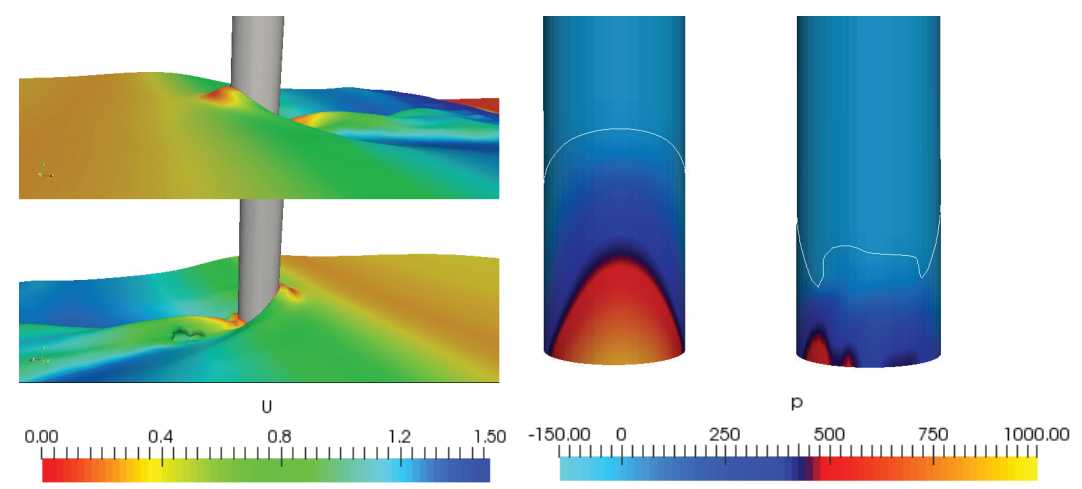

Figure 15: Snapshots of the overtopping flow and the pressure distribution around the cylinder at (a) $t=8.7 \mathrm{~s}$; (b) $t=8.85 \mathrm{~s}$; (c) $t=9.0 \mathrm{~s}$; (d) $t=9.15 \mathrm{~s}$ from the numerical simulation. At each time instant, the two figures on the left are the flow and velocity distribution around the cylinder from the front bird view and back bird view, respectively. The figures in the middle and right columns show the pressure distribution at the front and back faces of the cylinder. The white line on the cylinder denotes the instantaneous free surface position. 


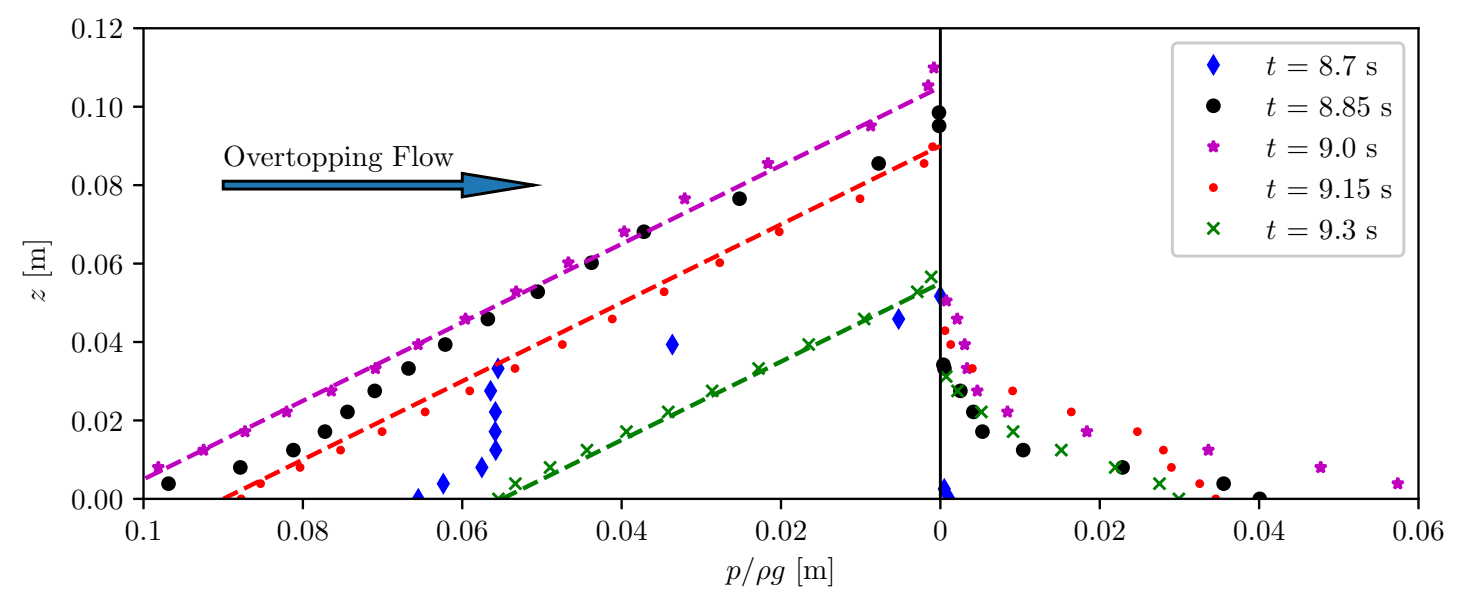

Figure 16: Vertical pressure distribution along the front and back stagnation line of the cylinder at the same time instants as in Fig. 15. The data are extracted from the numerical results. The dashed line is the hydrostatic pressure distribution along the front stagnation line when $z=0.105 \mathrm{~m}, z=0.090$ and $z=0.055 \mathrm{~m}$, respectively. The cylinder is located at $p / \rho g=0$.

depth and $U_{m}$ is the local maximum depth-averaged flow velocity, so the increase in flow velocity largely counteracts the reduction of the flow depth, resulting in a slower decay of the inline force on the cylinder.

\section{An empirical predictor for the maximum inline force}

As presented in Section 5 3D RANS simulation can reproduce the experiments fairly well. However, the simulation is computationally expensive. For instance, one needs approximately 24 - 48 hours on 24 cores in order to assess the inline force on human body under one regular wave condition. For irregular wave condition, the computation time is in order of weeks to get statistically meaningful results. Meanwhile, if we consider 2D RANS simulations, which means that only wave breaking and overtopping are resolved while its interaction with cylinder is not resolved, the computational time is significantly reduced. The overtopping flow depth can be easily obtained using a desktop even under irregular wave conditions. However, this requires us to develop a method to evaluate the inline force on the cylinder based on the overtopping flow depth, which is the objective of this section.

In this section, a predictor is developed based on the dimensional analysis shown in Section 2, which can be used to quickly estimate $F_{0 m}$ given the overtopping flow depth $d_{0 m}$ extracted from 2D RANS simulations. Then we develop an empirical formula, which expresses the maximum inline force at different locations $F_{m}$ as a function of $F_{0 m}$ and $x_{c}-x_{c 0}$, where $x_{c 0}$ is $1.5 D$ i.e., the position of the cylinder where $F_{0 m}$ was measured. Finally, we show a preliminary application of the predictor for wave overtopping force on a prototype-scale cylinder under an irregular wave condition. 

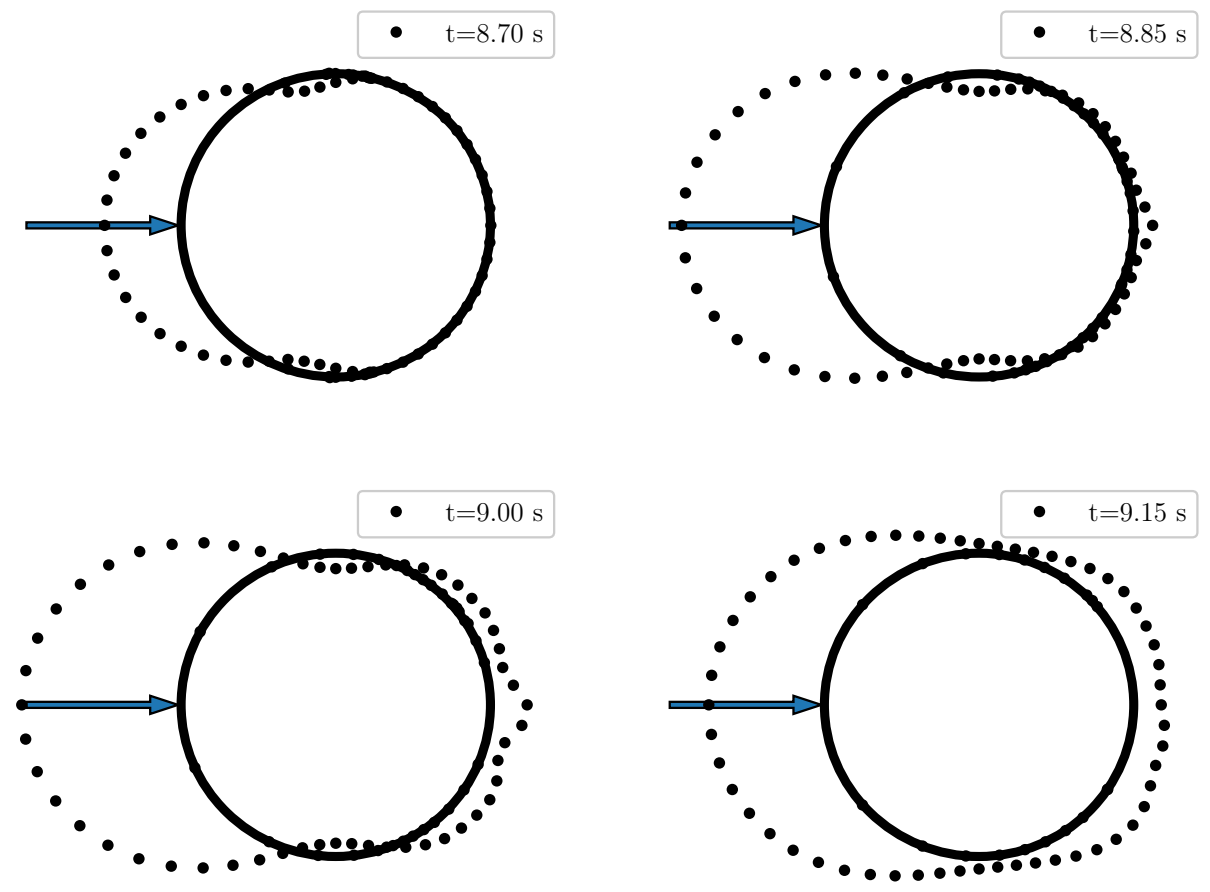

Figure 17: Distribution of the pressure integration in the circumference direction at the same time instants as in Fig. 15 The pressure is integrated from the bottom to the instantaneous free surface and the plot is scaled. The dots outside the cylinder represent positive pressure integration i.e., acting into the cylinder, and vice versa. The data are extracted from the numerical results.

\subsection{Derivation of the predictor}

The starting point of the derivation is Eq. (2), where the maximum inline force $F^{*}$ is shown to be determined by the wave steepness and relative freeboard. This equation can be converted to a scaling law for $F_{0 m}$

$$
F_{0 m}=C_{1}\left(\frac{H}{L_{0}}, \frac{R_{c}}{H}\right) \rho g H^{2} D
$$

where $C_{1}$ is a scaling parameter. We propose to replace $H$ with $d_{0 m}$, which is the maximum overtopping flow depth at the seawall's leading edge $x_{c}=0$. Note that $d_{0 m}$ is a function of the six independent variables

$$
H, T, R_{c}, \rho, \nu, g
$$

A dimensional analysis for $d_{0 m}$ (also neglect the viscous effect) yields

$$
d_{0 m}=C_{2}\left(\frac{H}{L_{0}}, \frac{R_{c}}{H}\right) H
$$



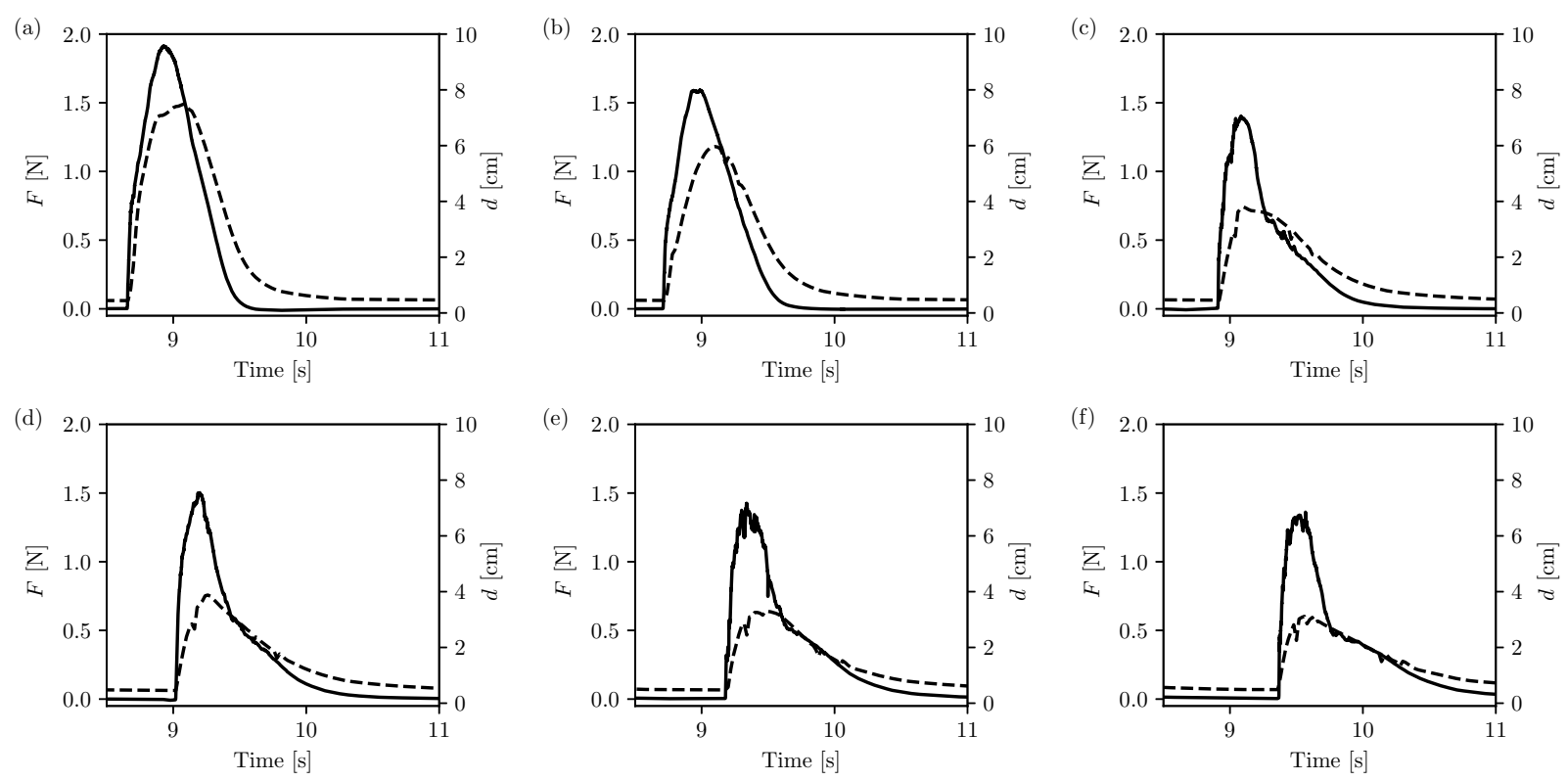

Figure 18: Time series of the inline force (solid line) and the overtopping flow depth (dash line) during one overtopping event. The data are extracted from the numerical model. The incident wave condition is $H=0.185 \mathrm{~m}, h=0.90 \mathrm{~m}, T=3 \mathrm{~s}$. The cylinder centre $x_{c}$ at each sub-figure is equal to (a) $x_{c}=0.09 \mathrm{~m}$; (b) $x_{c}=0.15 \mathrm{~m}$; (c) $x_{c}=0.39 \mathrm{~m}$; (d) $x_{c}=0.53 \mathrm{~m}$; (e) $x_{c}=0.78 \mathrm{~m}$; (f) $x_{c}=1.03 \mathrm{~m} . x_{c}=0$ corresponds to the leading edge of the seawall.

where $C_{2}$ is a parameter which relates the maximum water depth $d_{0 m}$ with the wave height $H$. By substituting Eq. (10) into Eq. (9), the following scaling law is obtained

$$
F_{0 m}=C_{d}\left(\frac{H}{L_{0}}, \frac{R_{c}}{H}\right) \rho g d_{0 m}^{2} D
$$

where $C_{d}$ is the scaling parameter when $F_{0 m}$ is expressed as a function of $d_{0 m}$.

Based on the dimensional analysis, the scaling parameter $C_{d}$ depends on the wave steepness $H / L_{0}$ and the relative freeboard $R_{c} / H$. In our periodic-wave-laboratory experiments, wave overtopping only occurs when $R_{c} / H<1$. There are only nine tests covering three wave period between $2-3 \mathrm{~s}$ and two target wave heights of $15 \mathrm{~cm}$ and $20 \mathrm{~cm}$, which are summarized in Table 3 . Despite of the small size, the laboratory dataset can still well illustrate the variations of $C_{d}$, which is also presented in Table 3 . It is found that there is no obvious variation of $C_{d}$ with $R_{c} / H$ or $H / L_{0}$. The obtained $C_{d}$ has a mean value of 0.40 and a standard deviation of 0.07 . Thus, we simply take a constant value of $C_{d}$ as

$$
C_{d}=0.40
$$

Using a constant value only introduces around $20 \%$ inaccuracy, which is acceptable. One possible reason for such little variation of $C_{d}$ is that the behaviour of the overtopping flow at vertical seawalls is weakly controlled by the two parameters, $R_{c} / H$ and $H / L_{0}$. The flow is always akin to a dam-break flow, which 
Table 3: Summary of the experimental data for the model tests with vertical seawall.

\begin{tabular}{cccccc}
\hline$R_{c}[\mathrm{~m}]$ & $T[\mathrm{~s}]$ & $H[\mathrm{~m}]$ & $d_{0 m}[\mathrm{~m}]$ & $F_{0 m}[\mathrm{~N}]$ & $C_{d}$ \\
\hline 0.10 & 2 & 0.14 & 0.035 & 0.31 & 0.43 \\
0.15 & 2 & 0.18 & 0.039 & 0.32 & 0.35 \\
0.10 & 2 & 0.18 & 0.081 & 1.20 & 0.31. \\
0.10 & 2.5 & 0.14 & 0.039 & 0.32 & 0.35 \\
0.15 & 2.5 & 0.18 & 0.036 & 0.42 & 0.54 \\
0.10 & 2.5 & 0.19 & 0.077 & 1.29 & 0.37 \\
0.10 & 3 & 0.14 & 0.047 & 0.47 & 0.37 \\
0.15 & 3 & 0.18 & 0.054 & 0.80 & 0.46 \\
\hline
\end{tabular}

starts with a large water depth and a low velocity at the leading edge. It should be noted that for calibration of $C_{d}$, only 9 experiments have been conducted. The reason has been explained in Section 2 and Section 3 that we focus on a relatively narrow parameter space with large uncertainty. This is also an important reason why $C_{d}$ is constant. However, in our case, it is sufficient to have a $C_{d}$ for $R_{c} / H=[0.53,0.83]$. As introduced at the beginning of this section, to complete the chain of prediction, 2D RANS simulations are required to provide $d_{0 m}$.

In order to further predict the decay of the inline force, the following formula is fitted to the data clouds that consist of both experiment and numerical data

$$
\frac{F_{m}(x)}{F_{0 m}}=\exp \left[-0.101\left(\frac{x_{c}-x_{c 0}}{d_{0 m}}\right)^{0.555}\right] \quad 0 \leq \frac{x_{c}-x_{c 0}}{d_{0 m}} \leq 20
$$

As shown in Fig. 19, the red solid line, which represents Eq. (13), nicely goes through the data cloud. In addition, most of the data points deviate from the fitting less than $20 \%$, which is represented by the two red dashed line. Therefore, Eq. 133 is expected to reasonably describe the variation of maximum inline force with the location on the seawall's crest.

\subsection{A preliminary application of the predictor}

In order to further validate the applicability of the predictor, a prototype-scale case study with irregular wave condition was performed. The cylinder has a $24 \mathrm{~cm}$ diameter and is located at $1.5 \mathrm{D}$ downstream from the leading edge of the seawall. The incident irregular wave condition is based on the JONSWAP spectrum with an enhancement factor of 3.3, a significant wave height of $0.6 \mathrm{~m}$ and a peak period of $4 \mathrm{~s}$. The water depth is $3.6 \mathrm{~m}$ and the freeboard is $0.4 \mathrm{~m}$.

Numerical simulations have been carried out to generate a time series of both inline force and overtopping flow depth. With the time series of the computed overtopping flow depths and cylinder diameter, the 


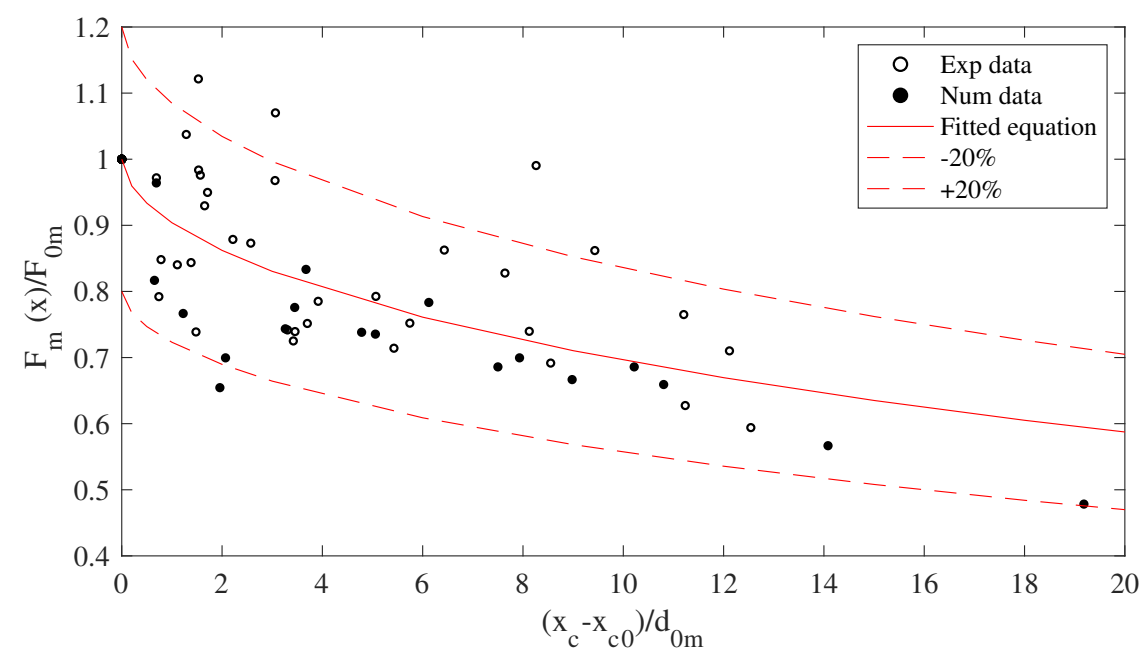

Figure 19: Decay of the nondimensional maximum inline force $F_{m} / F_{0 m}$ on the cylinder against the nondimensional cylinder's position $\left(x_{c}-x_{c 0}\right) / d_{0 m} . F_{m}$ is the dimensional maximum inline force and $F_{0 m}$ is the maximum inline force at the leading edge of the seawall's crest. $d_{0 m}$ is the maximum overtopping flow depth at the leading edge of the seawall's crest.

corresponding inline force is predicted using Eq. (11). Then the predicted and simulated maximum inline force are compared, which can be used to test the applicability of the predictor in irregular waves. With regard to the setup of the numerical model, the computational domain and mesh of the lab-scale simulations were directly scaled up to the prototype. This is justifiable, since the viscous effect is confirmed secondary, and the inline force is primarily governed by the inertia and gravity effects. Therefore, the main physics during the interaction process are still expected to be adequately resolved based on the geometrically upscaled mesh. For the present case, it took around one to two weeks to run a simulation with 40 - 50 wave cycles.

The simulated time series of the overtopping flow depth and the inline force on the cylinder are given in Fig. 20. During 180 seconds which corresponds to 45 wave cycles, there are totally 27 overtopping events, which are used to validate the predictor. Note that some very small overtopping events are not considered. The maximum overtopping event occurs at $t=132 \mathrm{~s}$, which produces an inline force of nearly $200 \mathrm{~N}$ on the cylinder. Using the simulated maximum overtopping depth as the input, the predictor can also produce a set of maximum inline force based on Eq. (11). The maximum inline forces produced from the predictor and the numerical model are compared in Fig. 21. In general, the agreement is reasonably good for all the overtopping event, though a slight underprediction is found. This is inevitable as we apply a constant scaling parameter for different incident wave heights. However, the underprediction is still within the $\pm 20 \%$ bound. The implication of this numerical application is that it is only necessary to predict the overtopping flow depth (i.e., $d_{0 m}$ ) using computationally affordable 2D RANS model in order to obtain the maximum inline force. Hence the high cost of resolving the cylinder using 3D RANS model is bypassed by using the simple predictor. 

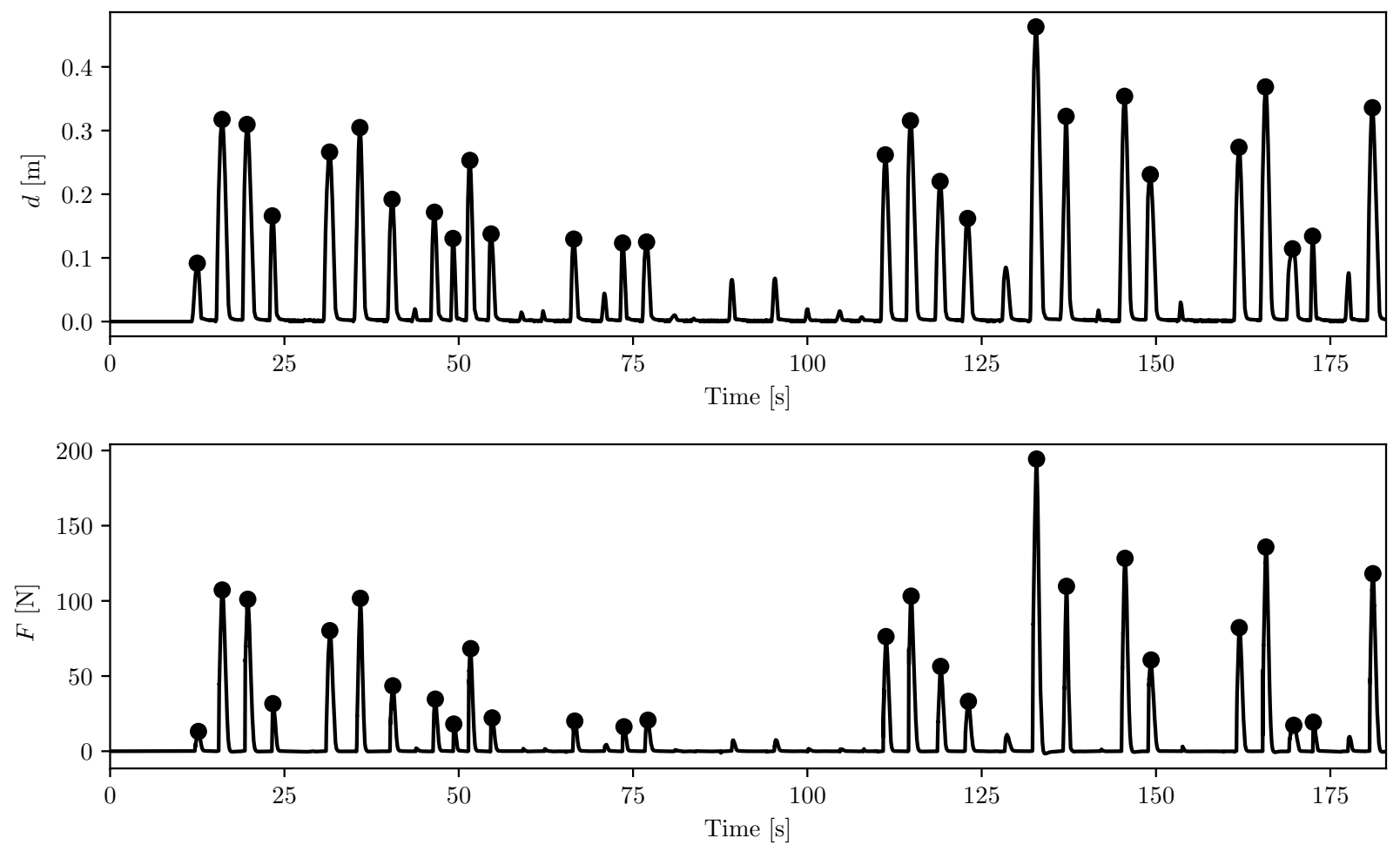

Figure 20: Time series of the simulated overtopping flow depth at the leading edge of the seawall (upper) and its induced force on the cylinder (lower) under an irregular wave condition at prototype scale. The dots are the selected peaks which are used to validate the empirical formula. The incident wave condition is the significant wave height $H_{s}=0.6 \mathrm{~m}$, peak period $T_{p}=4 \mathrm{~s}$ and water depth $h=3.8 \mathrm{~m}$. The waves were generated based on the JONSWAP spectrum with an enhancement factor of 3.3 .

\section{Concluding remarks}

In the present work, the inline force on a cylinder at a vertical seawall under non-breaking wave overtopping flow is investigated numerically and experimentally. The primary objectives of the present paper are on the following aspects: (1) evolution of the overtopping flow on the seawall's crest; (2) interaction between the overtopping flow and the cylinder; (3) decay of the inline force when the cylinder is moved inland; (4) development of a predictor for desktop computation of the inline force. The concluding remarks on these aspects are summarized below.

Wave overtopping on the vertical seawall is formed when the free surface at the seawall's boundary is elevated higher than the seawall. A small breaker is formed which entrains an air cavity. With the evolution of the overtopping flow, the cavity is deformed and further broken into small bubbles. The numerical results agree well with the experimental data in terms of the overtopping flow depth and the depth-averaged velocity, which are the most important quantities for the inline force on the cylinder. The initial size and the location of the air cavity are also adequately captured by the numerical model, but its deformation and breakup is 


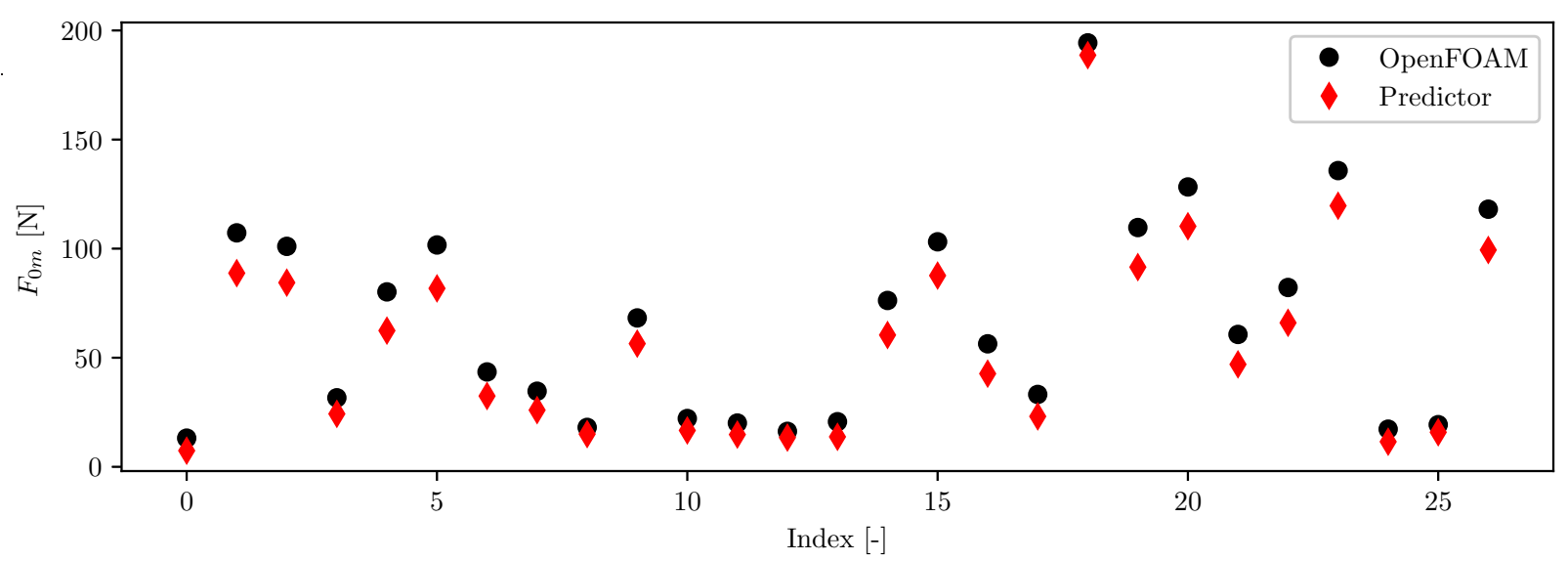

Figure 21: Comparison of the maximum inline force from the empirical predictor in Eq. 11 and the numerical simulations. The incident wave condition is the same as shown in Fig. 20

missed, as the cavity is simply advected by the overtopping flow in the numerical model.

Regarding the interaction between the overtopping flow and the cylinder, it is observed that the flow becomes locally 3-dimensional with a significant water pile-up in the front side of the cylinder. Based on the analysis of the pressure field around the cylinder, it is concluded that the inline force is primarily due to the difference of the pressure integration in the front and back sides of the cylinder. Viscous effects are secondary for the inline force on the cylinder. When the cylinder is moved further inland, the encountered local overtopping flow depth decreases significantly. However, the local depth-averaged velocity is observed to increase (up to twice of the velocity at the leading edge) within a distance of $x / d_{0 m}=5-10$ and then decrease. This results in a slow decay of the inline force on the cylinder.

Based on the dimensional analysis, an empirical predictor is developed, which can quickly provide an estimation of the inline force due to overtopping flow. The predictor requires the maximum overtopping flow depth at the seawall's ledge edge as a key input parameter. The scaling constant introduced in the predictor is calibrated based on the experimental and numerical data. It is applied to estimate the maximum inline force for a simulated prototype-scale case with irregular wave condition. A good agreement is found despite a slight underestimation. This demonstrates the applicability of the predictor, which has the potential to be used in practical engineering applications in the near future.

It should be noted here that the present study is limited to non-impulsive wave overtopping inline force on a circular cylinder at a deep vertical seawall without an influencing foreshore. It can be a basis for the risk assessment of the pedestrian in this type of seawall in the future. However, the findings in the present study may not be directly applicable to other types of seawall, like rubble mound type and impulsive vertical seawall. It is recommended that further studies be conducted to expand the method developed in the present paper to other types of seawalls. Also the ranges of test parameters in the present study can be further 
enlarged to test its validity in larger range of scope.

\section{Acknowledgement}

The authors would like to thank the two anonymous reviewers for their useful comments and suggestions, which have helped improve the quality of the paper significantly. This work was supported by the Climate Resilience Study Funds (CRSF) through Building and Construction Authority (BCA) and Public Utilities Board (PUB) of Singapore. The Department of Civil and Environmental Engineering in National University of Singapore is acknowledged for allowing us to use the hydraulic laboratory. National Supercomputing Centre Singapore (NSCC) is acknowledged for providing the high-performance computing facilities for the present study.

\section{References}

Allsop W, Bruce T, Pearson J, Alderson J, Pullen T. Violent wave overtopping at the coast, when are we safe? In: International Conference on Coastal Management 2003. Thomas Telford Publishing; 2003. p. 54-69.

Arrighi C, Oumeraci H, Castelli F. Hydrodynamics of pedestrians' instability in floodwaters. Hydrology and Earth System Sciences 2017;21(1):515-31. doi 10.5194/hess-21-515-2017

Brackbill JU, Kothe DB, Zemach C. A continuum method for modeling surface tension. Journal of computational physics 1992;100(2):335-54

Bredmose H, Bullock G, Hogg A. Violent breaking wave impacts. part 3. effects of scale and aeration. Journal of Fluid Mechanics 2015;765:82-113.

Bredmose H, Hunt-Raby A, Jayaratne R, Bullock G. The ideal flip-through impact: experimental and numerical investigation. Journal of engineering mathematics 2010;67(1-2):115-36.

Bredmose H, Peregrine D, Bullock G. Violent breaking wave impacts. part 2: modelling the effect of air. Journal of Fluid Mechanics 2009;641:389-430.

Bullock G, Obhrai C, Peregrine D, Bredmose H. Violent breaking wave impacts. part 1: Results from large-scale regular wave tests on vertical and sloping walls. Coastal Engineering 2007;54(8):602-17.

Castellino M, Sammarco P, Romano A, Martinelli L, Ruol P, Franco L, De Girolamo P. Large impulsive forces on recurved parapets under non-breaking waves. a numerical study. Coastal Engineering 2018;136:1-15.

Chen X, Hofland B, Altomare C, Suzuki T, Uijttewaal W. Forces on a vertical wall on a dike crest due to overtopping flow. Coastal Engineering 2015;95:94-104. doi 10.1016/j.coastaleng.2014.10.002

Chen X, Hofland B, Uijttewaal W. Maximum overtopping forces on a dike-mounted wall with a shallow foreshore. Coastal Engineering 2016;116:89-102. URL: http://dx.doi.org/10.1016/j.coastaleng.2016.06.004 doi 10.1016/j.coastaleng. 2016.06 .004

Chu P, Finch J, Bournival G, Ata S, Hamlett C, Pugh RJ. A review of bubble break-up. Advances in Colloid and Interface Science 2019;270:108-22. URL: https://doi.org/10.1016/j.cis.2019.05.010 doi 10.1016/j.cis.2019.05.010

Cooker M, Peregrine D. Violent motion as near breaking waves meet a vertical wall. In: Breaking waves. Springer; 1992. p. $291-7$.

Cuomo G, Allsop W, Bruce T, Pearson J. Breaking wave loads at vertical seawalls and breakwaters. Coastal Engineering 2010;57(4):424-39. URL: http://dx.doi.org/10.1016/j.coastaleng.2009.11.005 doi 10.1016/j.coastaleng.2009. 11.005 
De Rouck J, Van Doorslaer K, Versluys T, Ramachandran K, Schimmels S, Kudella M, Trouw K. Full scale impact tests of an overtopping bore on a vertical wall in the large wave flume (gwk) in hannover. Coastal Engineering Proceedings 2012;1(33):structures-62.

Endoh K, Takahashi S. Numerically modelling personnel danger on a promenade breakwater due to overtopping waves. Proceedings of 24th International Conference on Coastal Engineering 1995;:1016-29.

EurOtop . Manual on wave overtopping of sea defences and related structures. an overtopping manual largely based on european research, but for worldwide application. Van der Meer, J W and Allsop, N W H and Bruce, T and De Rouck, J and Kortenhaus, A and Pullen, T and Schüttrumpf, H and Troch, P and Zanuttigh, B 2018;.

Greco M, Faltinsen OM, Landrini M. Shipping of water on a two-dimensional structure. Journal of Fluid Mechanics 2005;525(June 2003):309-32. doi 10.1017/S0022112004002691

Guo X, Wang B, Liu H, Miao G. Numerical Simulation of Two-Dimensional Regular Wave Overtopping Flows over the Crest of a Trapezoidal Smooth Impermeable Sea Dike. Journal of Waterway, Port, Coastal, and Ocean Engineering 2013;140(3):04014006. doi 10.1061/(asce)ww.1943-5460.0000234.

Hirt CW, Nichols BD. Volume of fluid (vof) method for the dynamics of free boundaries. Journal of computational physics $1981 ; 39(1): 201-25$.

$\mathrm{Hu}$ Z, Xue H, Tang W, Zhang X. A combined wave-dam-breaking model for rogue wave overtopping. Ocean Engineering 2015;104:77-88. URL: http://dx.doi.org/10.1016/j.oceaneng.2015.05.009 doi 10.1016/j.oceaneng.2015.05.009

Jacobsen NG, Fuhrman DR, Fredsøe J. A wave generation toolbox for the open-source CFD library: OpenFoam $\mathbb{R}$. International Journal for Numerical Methods in Fluids 2012;70(9):1073-88. URL: http://doi.wiley.com/10.1002/fld.2726 doi 10.1002/ fld.2726 arXiv:fld.1

Jensen B, Jacobsen NG, Christensen ED. Investigations on the porous media equations and resistance coefficients for coastal structures. Coastal Engineering 2014;84:56-72. URL: http://dx.doi.org/10.1016/j.coastaleng.2013.11.004. doi:10. $1016 / j$.coastaleng.2013.11.004

Jonkman S, Penning-Rowsell E. Human instability in flood flows 1. JAWRA Journal of the American Water Resources Association 2008;44(5):1208-18.

Kisacik D, Tarakcioglu GO, Baykal C. Stilling wave basins for overtopping reduction at an urban vertical seawall - The Kordon seawall at Izmir. Ocean Engineering 2019;185(May):82-99. doi 10.1016/j.oceaneng.2019.05.033

Kristiansen T, Faltinsen OM. Higher harmonic wave loads on a vertical cylinder in finite water depth. Journal of Fluid Mechanics 2017;833:773-805. doi 10.1017/jfm.2017.702

Liao Y, Lucas D. A literature review of theoretical models for drop and bubble breakup in turbulent dispersions. Chemical Engineering Science 2009;64(15):3389-406.

Lind N, Hartford D, Assaf H. Hydrodynamic models of human stability in a flood 1. JAWRA Journal of the American Water Resources Association 2004;40(1):89-96.

Lugni C, Brocchini M, Faltinsen O. Wave impact loads: The role of the flip-through. Physics of fluids 2006;18(12):122101.

Mares-Nasarre P, Argente G, Gómez-Martín ME, Medina JR. Overtopping layer thickness and overtopping flow velocity on mound breakwaters. Coastal Engineering 2019;154:103561.

Martinelli L, Ruol P, Volpato M, Favaretto C, Castellino M, De Girolamo P, Franco L, Romano A, Sammarco P. Experimental investigation on non-breaking wave forces and overtopping at the recurved parapets of vertical breakwaters. Coastal Engineering 2018;141(July):52-67. doi 10.1016/j.coastaleng.2018.08.017

Martínez-Gomariz E, Gómez M, Russo B. Experimental study of the stability of pedestrians exposed to urban pluvial flooding. Natural hazards 2016;82(2):1259-78.

Van der Meer J, Bruce T. New physical insights and design formulas on wave overtopping at sloping and vertical structures. Journal of Waterway, Port, Coastal, and Ocean Engineering 2014;140(6):04014025. 
Van der Meer JW, Hardeman B, Steendam GJ, Schüttrumpf H, Verheij H. Flow depths and velocities at crest and inner slope of a dike, in theory and with the wave overtopping simulator. Proceedings of 32nd International Conference on Coastal Engineering 2011;:1-15.

Milanesi L, Pilotti M, Ranzi R. A conceptual model of people's vulnerability to floods. Water Resources Research 2015;51(1):182-97.

Paulsen BT, Bredmose H, Bingham HB, Jacobsen NG. Forcing of a bottom-mounted circular cylinder by steep regular water waves at finite depth. Journal of Fluid Mechanics 2014;755:1-34. doi 10.1017/jfm.2014.386

Roenby J, Bredmose H, Jasak H. A computational method for sharp interface advection. Royal Society Open Science 2016;3(11). doi $10.1098 /$ rsos.160405

Romano A, Bellotti G, Briganti R, Franco L. Uncertainties in the physical modelling of the wave overtopping over a rubble mound breakwater: The role of the seeding number and of the test duration. Coastal Engineering 2015;103:15-21. URL: http://dx.doi.org/10.1016/j.coastaleng.2015.05.005 doi 10.1016/j.coastaleng.2015.05.005

Ryu Y, Chang KA, Mercier R. Application of dam-break flow to green water prediction. Applied Ocean Research $2007 ; 29(3): 128-36$.

Schüttrumpf H, Oumeraci H. Layer thicknesses and velocities of wave overtopping flow at seadikes. Coastal Engineering $2005 ; 52(6): 473-95$.

Thielicke W, Stamhuis E. Pivlab-towards user-friendly, affordable and accurate digital particle image velocimetry in matlab. Journal of Open Research Software 2014;2(1).

Van Bergeijk VM, Warmink JJ, van Gent MR, Hulscher SJ. An analytical model of wave overtopping flow velocities on dike crests and landward slopes. Coastal engineering 2019;149:28-38.

Zhang X, Draper S, Wolgamot H, Zhao W, Cheng L. Eliciting features of 2D greenwater overtopping of a fixed box using modified dam break models. Applied Ocean Research 2019;84(July 2018):74-91. doi 10.1016/j.apor.2019.01.006 